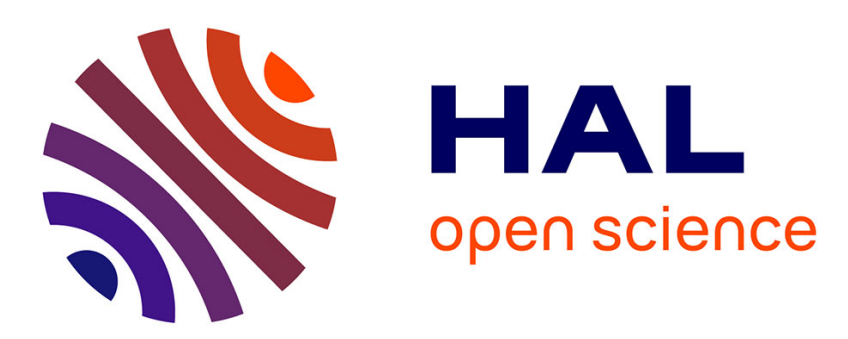

\title{
High-precision dating of ceremonial activity around a large ritual complex in Late Bronze Age Mongolia
}

Antoine Zazzo, Sébastien Lepetz, Jérôme Magail, Jamyian-Ombo Gantulga

\section{To cite this version:}

Antoine Zazzo, Sébastien Lepetz, Jérôme Magail, Jamyian-Ombo Gantulga. High-precision dating of ceremonial activity around a large ritual complex in Late Bronze Age Mongolia. Antiquity, 2019, 93 (367), pp.80-98. 10.15184/aqy.2018.175 . hal-02348791

\section{HAL Id: hal-02348791 \\ https://hal.science/hal-02348791}

Submitted on 5 Nov 2019

HAL is a multi-disciplinary open access archive for the deposit and dissemination of scientific research documents, whether they are published or not. The documents may come from teaching and research institutions in France or abroad, or from public or private research centers.
L'archive ouverte pluridisciplinaire HAL, est destinée au dépôt et à la diffusion de documents scientifiques de niveau recherche, publiés ou non, émanant des établissements d'enseignement et de recherche français ou étrangers, des laboratoires publics ou privés. 


\section{ANTIQUITY \\ a review of world archaeology}

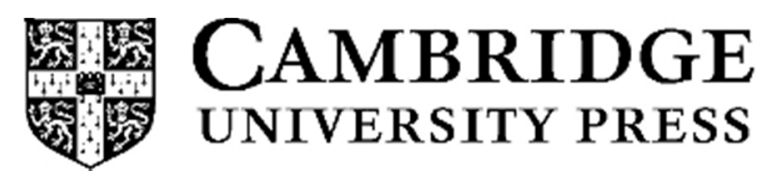

\section{High-precision dating of ceremonial activity around a large ritual complex in Late Bronze Age Mongolia}

\begin{tabular}{|r|l|}
\hline Journal: & Antiquity \\
\hline Manuscript ID & AQY-RE-18-003.R2 \\
\hline Manuscript Type: & Research \\
\hline Complete List of Authors: & $\begin{array}{l}\text { Zazzo, Antoine; CNRS - MNHN, Homme et Environnement; } \\
\text { Lepetz, Sébastien; CNRS - MNHN, Homme et Environnement } \\
\text { Magail, Jérôme ; Musée d'Anthropologie préhistorique de Monaco, 56 bis, } \\
\text { Boulevard du Jardin Exotique } \\
\text { Gantulga, Jamiyan-Ombo; Mongolian Academy of Sciences, Institute of } \\
\text { History and Archaeology }\end{array}$ \\
\hline Keywords: & Mongolia, Bronze Age, Radiocarbon dating, Bayesian modeling, Monument \\
\hline Research Region: & Other Asia \\
\hline \multicolumn{2}{|c}{} \\
\hline
\end{tabular}

\section{SCHOLARONE \\ Manuscripts}




\title{
High-precision dating of ceremonial activity around a large ritual complex in Late Bronze Age Mongolia
}

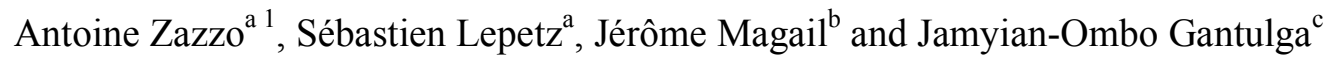 \\ ${ }^{a}$ UMR 7209, Archéozoologie, Archéobotanique : Sociétés, Pratiques et Environnements, \\ CNRS, MNHN, Sorbonne Universités, CP 56, 55 rue Buffon, F-75005 Paris, France \\ ${ }^{\mathrm{b}}$ Musée d'Anthropologie préhistorique de Monaco, 56 bis, Boulevard du Jardin Exotique, MC \\ 98 000, Monaco \\ ${ }^{\mathrm{c}}$ Institute of History and Archaeology, Mongolian Academy of Sciences, Jucov street-77, \\ Ulaanbaatar-13343, Mongolia
}

${ }^{1}$ To whom correspondance may be addressed. Email: zazzo@mnhn.fr 


\section{Introduction}

Most of the archaeological culture of the Eurasia's eastern steppes is apprehended through its rich monumental landscape. Among these, deer stones and khirgisuurs (DSK) complexes are iconic monuments that form the main components of a mortuary ceremonial system dating to the Late Bronze Age (ca. 1200-700 BCE). These monuments are part of the larger "kurgan" tradition of the Eurasian steppe and are found mostly in central and northern Mongolia, but also in northwestern China and southern Siberia (Allard \& Erdenebaatar 2005; Amartuvshin 2007; Erdenebaatar 2000). Khirgisuurs are composed of a central stone mound covering a stone burial chamber, usually containing the remains of a single human body. The central mound, which can reach an average diameter of about $10 \mathrm{~m}$, is surrounded by a circular or quadrangular fence formed by an alignment of stones. Most of them also include external structures in the form of stone circles and stone mounds. Stone circles are made up of between seven and twelve stones and often contain the calcined bone elements of domestic animals (mostly caprines, but sometimes also bovines). Stone mounds consist of local rocks heaped to between 1 and $5 \mathrm{~m}$ in diameter, covering the head of a horse facing east together with the neck and hoof elements. Recent work has demonstrated that these horses also were domesticated and used for chariotry or mounted ridding, highlighting the importance of the horse in the development of mobile pastoralism during the Late Bronze Age (Taylor 2017). The archaeological context suggests that these remains are linked to a ritual practice but in the absence of decisive data to define the meaning of the gesture it is difficult to determine whether them come from sacrificed animals or if they are offerings. The number of associated peripheral structures varies from zero to several thousands and as a result, khirgisuurs range widely in size from 0.1 to 20 ha. However, the vast majority of khirigsuurs are of moderate size and very large monuments are rare. Deer stones are anthropomorphic stelae often covered with deer carvings (Volkov 2002; Jacobson-Tepfer 2001; Fitzhugh 2009a). Like khirgisuurs, they are often accompanied by peripheral stone mound and stone circle structures and indeed include the same sacrificial offerings of domestic animals.

The wide distribution of these elaborate burial mounds and stone monuments suggests shared knowledge between individuals and mobile communities across the eastern steppe and indicates a level of socio-political intensification and complexity previously unknown in this region. Despite the fact that khirgisuurs have been the focus of attention for several scholars over the past decade, many questions regarding their ritual and funerary role as well as their social and political function remain unanswered. Based on the analysis of form and architecture some authors suggested that their construction was planned and swiftly executed 
(Fitzhugh 2009b; Houle 2017) and regarded these monuments as evidence for the beginning of social inequality on the Mongolian plateau (Honeychurch et al. 2009). Indeed, a significant amount of collective work was required to build them and variations in their number and size have been interpreted as reflecting differences in wealth between communities (Wright 2014) and/or in the social status of individuals (Frohlich et al. 2008). Joshua Wright also identified khirgisuurs which appear to have "accreted" over continual reuse (Wright 2014). He argued that khirgisuurs were living monuments that were built to be repeatedly visited and modified, highlighting their role at materializing communal cohesion through social interactions in an egalitarian society. The size of the community involved in the construction of these large monuments is also unknown. If we assume that large khirgisuurs are elaborated in an instant, then the animals slaughtered (sometimes more than a thousand of horses) must come from an area much larger than the local community and would be representative of social networks active over great distances (Houle 2017). On the contrary, repeated use over several decades would not necessarily require the involvement of very distant populations.

Addressing the debate on the timing of construction of large khirgisuurs is therefore essential if we are to better understand the social political structure of LBA societies. Houle (2017) pointed out that some of the structural elements like the position of the surrounding fence and the mounds closest to the fence outwards imply planning and simultaneous execution. But whether ritual features such as stone mounds and stone circles were built during a single ceremony or a prolonged period of time remains a matter of speculation, owing to the relatively small number of radiocarbon dates available so far (Allard \& Erdenebaatar 2005; Fitzhugh \& Bayarsaikhan 2009). For the same reason, the construction history of complexes in which deer stones and khirigsuurs appear together is also unclear at the site level, some viewing them as synchronous while others see deer stones as later intrusions in an already ritually sanctified ground (Fitzhugh 2009a; Jacobson-Tepfer 2001).

To our knowledge, only two large khirgisuurs have more than two AMS dates: Urt Bulagyn and the B10 complex of Tsatsyn Ereg, both located in central Mongolia (Arkhangaï aimag). Urt Bulagyn is located in the Khanuy Valley. It covers about 15 ha and contains ca. 2700 peripheric structures out of which only four have been excavated and dated (Allard \& Erdenebaatar 2005; Fitzhugh \& Bayarsaikhan 2009). The calibrated dates suggest a possible outward growth for the satellite mound sector over a period of a few hundred years between the $11^{\text {th }}$ and the $7^{\text {th }} \mathrm{c}$ BCE (Table S1 Fig S1). The B10 complex of Tsatsyn Ereg is located 50 $\mathrm{km}$ southeast of Urt Bulagyn in the Khoid Tamir Valley (Magail 2008a). This large khirgisuur 
covers about 22 ha and contains 2361 peripheral structures (Fig. 1). The radiocarbon dating of six ritual structures associated to the B10 complex suggests an extensive period of use for this khirgisuur from about the $11-10^{\text {th }}$ to the $4-2^{\text {nd }}$ c. BCE (Gantulga 2015). If confirmed, the prevalence of the same ceremonial activity over several centuries would be unprecedented archaeologically and raise questions regarding its significance and function. However, for reasons exposed in more detail in the SI Appendix we consider it likely that contamination of bone collagen with modern carbon affected the results.

Khirgisuurs were key features of the social and physical landscape of the Late Bronze Age. The debate about their significance regarding their date and construction histories has implications for wider understanding about demography, mobility, and regional networks:

a) built at as a single event, drawing on large regional networks for people and animals; b) built across a human lifetime, with less necessity for regional resources/implications for local social and demographic organisation

c) built over a century or more, and requiring still fewer regional resources and perhaps more localism.

It is therefore of uttermost importance to develop tight chronological control for these monuments of Central Mongolia with respect to sociopolitical development at this crucial time period. Bayesian modeling can be used to test these hypotheses, but they require large quantities of AMS dates on well-preserved samples, which can be challenging in the case of khirigisuurs becauses bones are shallowly buried and exposed to weathering. This article aims at providing the first high precision data of ceremonial activity that tie deer stone complexes together with a large and a small khirgisuur complex. We do so by dating a large number of horse and caprines deposited at the site of Tsatsyn Ereg and applying a Bayesian modeling treatment to the data. We also address the issue of bone contamination and its impact on radiocarbon dates and discuss the broader significance of our results for understanding of the Mongolian Bronze Age.

\section{The Late Bronze Age monuments of the Khoid Tamir Valley}

Since 2006, the joint Monaco-Mongolia archaeological mission carries out research at the Late Bronze Age to Early Iron Age site of Tsatsyn Ereg (Arkhangaï province, Khoid Tamir Valley) (Magail 2008b; Magail 2015). Within the surveyed area (ca. $150 \mathrm{~km} 2$ ) more than 2100 graves, over 110 deer stones and three thousands of petroglyphs have been documented so far (Fig. 2). The material included in this study derives from the excavation of 
three archaeological complexes located in the Khoid Tamir Valley: a small khirgisuur (KTS01), a large khirgisuur (B10) and structures in close association with a deer stone (PAC38). A detailed description and analysis of each distinct ritual feature and its possible function in funerary or mortuary practice is beyond the scope of this article and will be the focus of a separate contribution (Lepetz et al., forthcoming). Briefly, KTS-01 presents seven peripheral structures which were all excavated in 2012 (Fig. 3). Six out of the seven mounds contained the remains of horses which were sampled for radiocarbon dating. The deer stone PAC38 is associated with 144 mounds, of which three were excavated in 2011 (Fig. 4). Each excavated mound contained the remains of a horse which was sampled for radiocarbon dating. The large khirgisuur B10 covers a surface of about 22 ha and contains 2361 peripheral structures, including 1116 mounds and 1245 circles (Fig. 5 and 6). The size and architectural plan of this khirgisuur is very similar to that of Urt Bulagyn located ca. $50 \mathrm{~km}$ north-west (Allard \& Erdenebaatar 2005). Between 2009 and 2016, a total of sixty structures were excavated including 22 circles and 38 mounds. The structures were selected in order to cover a wide topographical range. Twenty out of the 22 circles contained datable material, either calcined bone, charcoal or both, which were sampled for radiocarbon dating. While some mounds were empty (8/38), most of them provided one, sometimes two horse heads together with the neck and hoof elements. When two individuals were found in the same mound, both were sample. Collagen was extracted from the horse bones and teeth from the three excavated complexes: KTS-01, B10 and PAC38. Two different collagen extraction methods were used, including ultrafiltration. The results are described and summarized in SI Appendix (Table S2 and Fig. S7-11). The discussion below first examines the impact of diagenetic alteration on the radiocarbon dates. Then, carefully scrutinized samples are integrated into a high precision Bayesian model in order to precise the chronology of the LBA monuments.

\section{Result and Discussion}

\section{Assessing the effect of diagenesis on radiocarbon ages}

The ages measured in calcined bones and charcoal from the B10 complex cluster tightly between $2770 \pm 20$ and $2910 \pm 25$ BP. Pairs of calcined bone and charcoal dates were either very close or identical (SI Appendix, Fig. S2), indicating good preservation of the calcined bone apatite, in keeping with previous results obtained for this type of material (Lanting et al. 2001; Chatters et al. 2017). On the contrary, the ages measured in bone collagen samples from this khirgisuur appear more variable, ranging between $2630 \pm 25$ and $2925 \pm 25$ BP. The chemical integrity of the molecule was assessed independently of the 
measured age using collagen yield and C/N ratio as proxies (DeNiro 1985; Ambrose 1990; van Klinken 1999). All the samples fulfilled the conditions for well-preserved bones, with collagen yields above $1 \%$ and $\mathrm{C} / \mathrm{N}$ ratios comprised between 2.9 and 3.6 (DeNiro 1985; Ambrose 1990; van Klinken 1999; Brock et al. 2010). But the correlation between the collagen $\mathrm{C} / \mathrm{N}$ ratios and the ${ }^{14} \mathrm{C}$ ages observed at KTS01 (SI Appendix, Fig. S3) and at the B10 complex (SI Appendix, Fig. S4), together with the age difference between the high molecular weight (HMW) and the low molecular weight (LMW) fractions of the ultrafiltered bone collagen samples (Fig. S5) indicate that some of the bone collagen samples were contaminated by a young, ${ }^{14} \mathrm{C}$-depleted source of carbon, probably coming from the soil. Because the horse skulls were placed directly on, or just below the surface of the paleosol some 3000 years ago, they were continuously exposed to weathering and often had roots and fungi penetrating deep into them. This contamination could not have been detected solely on the quality control (QC) criteria routinely applied. In order to investigate whether ultrafiltration successfully removed this contamination, we compared the dates measured on the same samples treated with the two methods using the HMF results only for Method 2. The results are presented in the SI Appendix (Fig. S6) and show that there was no systematic difference between the ${ }^{14} \mathrm{C}$ age of bones treated with or without ultrafiltration. Only four ultrafiltered bones (in ST15, ST17, SAT533 and SAT 803) returned dates that were significantly $\left(>50{ }^{14} \mathrm{C}\right.$ y) older than non-ultrafiltered bones, while the opposite situation was observed on two occasions (ST6 and ST8). On average, the ${ }^{14} \mathrm{C}$ dates measured on ultrafiltered collagen were slightly older and less variable than without ultrafiltration $(2806 \pm 58$ BP vs $2785 \pm 87$ BP $n=15)$ but not significantly different $(p=0.41)$, thus suggesting that ultrafiltration is not the solution.

Our results strongly suggest that the QC criteria for collagen purity are not strict enough for accurately dating the B10 complex and associated structures and should be revised, at least for bones found in similar contexts (subsurface finds from mid-latitude sites). For this reason, only collagen samples with $\mathrm{C} / \mathrm{N}$ ratios of 3.30 or below and extraction yields of $5 \%$ or above were considered not significantly contaminated. For ultrafiltered samples, we can only rely on the $\mathrm{C} / \mathrm{N}$ ratio because lower collagen yields are typically obtained from poorly preserved samples (Higham et al. 2006). This approach lead us to discard about half (34/65) of the samples for the large khirgisuur B10, 4/6 samples for STE01 and 0/3 samples for PAC38. It is noteworthy that most of the contaminated samples were from petrous bones, while most of the samples with well-preserved collagen were from tooth roots and dentine. We postulate that the physical protection of dentine by tooth enamel probably explains this 
differential preservation within a single horse skull. Using these revised QC criteria, the radiocarbon age of the remaining collagen samples ranged from $2780 \pm 252915 \pm 25 \mathrm{BP}$ and are undistinguishable from the circle dates. We tested the accuracy of the new QC criteria by comparing the ${ }^{14} \mathrm{C}$ age of samples that had been dated twice. This is the case in SAT 810 and ST 5 where collagen from the same individual bone was extracted using two different methods and in SAT 354 where two different bones were dated. In each case, the ${ }^{14} \mathrm{C}$ ages did not significantly differ (T-test, $\mathrm{p}<.001$ ). We also show that once the revised QC criteria are applied, there is no more correlation between collagen age and either collagen yield $(\mathrm{r} 2=0.15)$ or $\mathrm{C} / \mathrm{N}$ ratio $(\mathrm{r} 2=0.02)$. This gives us confidence in the fact that the samples that passed the new QC criteria are not significantly contaminated and that their ${ }^{14} \mathrm{C}$ age is reliable.

\section{Bayesian modeling}

The radiocarbon dates of the selected samples (31 bone collagen, 20 calcined bones and 6 charcoal from the B10 complex, 2 bone collagen from the KTS01 khirgisuur and 3 bone collagen from the deer stone PAC38) were used to generate a high resolution sequence using Bayesian modeling. The principle this modeling technique is to combine radiocarbon dates with prior information to produce a posterior density estimate which combines both sorts of evidence. A high overall agreement of the model (by convention, $60 \%$ or above) will indicate that the posterior distribution agrees well with the prior distribution and that the prior information and the radiocarbon dates are consistent. On the contrary, a low overall agreement for the model will indicate that both the standardized likelihood and prior belief have to be reassessed. In the case of a monument like the B10 complex, adding prior information is not trivial because the dated material comes from structures that are not linked by any stratigraphic relationship. For this reason, we used only weak or non-informative prior to estimate the onset, duration and end of use of the B10 complex. To assess the relationship of the B10 complex with the other two dated structures, we also modeled the onset, duration and end of use of PAC38 and KTSE01. We used the resulting sample of 62 dates, and produced a Bayesian model containing three phases corresponding to the three dated monuments with a uniform prior using the OxCal and the IntCal13 radiocarbon calibration curve (Bronk-Ramsey \& Lee 2013). We then used the OxCal 'Order' function in order to test the chronological ordering between the different monuments. We repeated this analysis again with an outlier model which identifies and downweights anomalous measurements (Bronk Ramsey 2009). Details of the models can be found in the SI Appendix (S4.A). Both models produced similar results, but only results from the outlier model are reported here. The model 
was run five times to assess its reproducibility and the data from one of the runs are shown in Table 1. We then used the OxCal 'Order' function in order to test the chronological ordering between the different monuments.

The results provided an age model that precisely dated the onset, duration and end of use of the three monuments (Figure 7). The model suggested that the construction of the horse and caprine ritual structures in the B10 complex started during the second half of the $11^{\text {th }} \mathrm{c}$. BCE (1057-1007 cal. BCE, 95.4\%) and ended during the first half of the $10^{\text {th }} \mathrm{c}$. BCE (1014948 cal. BCE, 95.4\%). The overall span of use of the B10 complex was comprised between 093 y $(95.4 \%)$ with a median value of 41 y (Fig. 8). For PAC38, the results suggest that the construction of satellite features started 1337-945 cal. BCE and ended 1060-684 cal BCE (95.4\%). The overall span is comprised between 0-113 y with a median value of $32 \mathrm{y}$. For KTS01, the results suggest that the construction of satellite features started 1532-1017 cal. BCEE (90.9\%, median 1143) and ended 1122-619 cal BCEE (90.9\%, median 998). The overall span is comprised between $0-103 \mathrm{y}$ with a median value of $22 \mathrm{y}$. The test for the ordering of the three structures suggested that there was a high probability (98.2\%) that the small khirgisuur KTS01 was constructed before the B10 complex and the deer stone PAC38 (79.8\%) (Table 2). On the contrary, the start of the B10 complex and the PAC38 area cannot be chronologically differentiated, highlighting a probable connection between deer stones and large khirgisuurs, as already proposed (Fitzhugh 2009a; Taylor et al. 2017). It is noteworthy that the boundaries for the PAC38 and KTS01 are less precise than for the B10 complex due to the limited number of radiocarbon dates available for modeling.

Our results show with a high degree of confidence that the 2361 peripheral structures of the B10 complex were constructed over a fairly short period of time, probably within a generation. However what the model does not effectively distinguish is whether the B10 complex was built essentially in an instant - in a single event - or whether it was built over a longer period of time. Indeed, the 2-sigma confidence interval for the span of construction ( 0 $93 \mathrm{yrs}$ ) includes 0 and additional simulation is required to address this question meaningfully. To decipher the different scenarios, we built three models which used fictitious bone and charcoal dates, following (Bayliss 2007). Details of the models can be found in the $S I$ Appendix (S4.B-D). The three models show the calibrated dates integrated in a single phase to mimic the real dataset for the B10 complex. The dates have been simulated by a process of back calibration from samples whose real age is centered around $1000 \mathrm{cal} \mathrm{BC}$ as suggested by the results of the previous model. In the first model (Model 0), we hypothesized that all the peripheral structures were built in a single event and date from $1000 \mathrm{cal} \mathrm{BC}$; in the second 
model (Model 50), we hypothesized that the peripheral structures were constructed over 50 yrs, between 1025 and 975 cal BC; in the third model (Model 100), we hypothesized that the peripheral structures were constructed over $100 \mathrm{yrs}$, between 1050 and $950 \mathrm{cal} \mathrm{BC}$. The results provided age models that precisely dated the onset, duration and end of use of the B10 complex Table 3. The comparison of the shape of the probability distribution for the real data (Fig 8) and the three simulations (Fig. 9) allow us to discard the single-event model (Model 0) because in this model, the highest probability is predicted for a span of 0 yrs (median $15 \mathrm{yrs}$ ). We can also exclude Model 100 which does not include 0 in the modeled span. The best match is found with the intermediate simulation (Model 50) both in terms of model outputs (onset, duration and end of use) and in terms of the shape of the probability distribution of the span, suggesting that the B10 complex was built over a period of about 50 yrs.

Several functions have been attributed to large DSK complexes. While large monuments of the Mongolian Bronze Age are often presented as the earliest expression of elite power and inequality (Allard \& Erdenebaatar 2005; Fitzhugh 2009a; Houle 2009), others prefer to see them as instruments of trans-egalitarian interactions and invoke their importance as structuring elements of Bronze Age societies (Wright 2014). While the data and analysis presented here do not call into question the assumptions about the significance of large complexes, they are an essential anchor for the theoretical models proposed. For the first time, it also becomes possible to make some inference regarding the size of the population that built large DSK complexes such as that of Tsatsyn Ereg. In Mongolia today, households usually slaughter a horse per year, at the beginning of winter (Marchina et al. 2017). Modern ethnographic observations also show that in Central Mongolia, horse skulls are deposited annually on the top of ovoos (Marchina et al. 2017). Assuming a similar practice in the Late Bronze Age, we calculated that twenty-five family units/households would have been able to slaughter the ca. 1260 horses (corresponding to the 1116 and 144 mounds of B10 and PAC38, respectively) over the period of 50 years proposed based on our model. The different polygonal or linear arrangements of mounds observed at khirgisuur B10 include 10 to 15 mounds could then well represent these synchronous (possibly annual) events. Given the similarity between the number of stone mounds and stone circles, the deposition of burnt caprine bones could have occurred at the same rate, either at the same time as deposition of the horse heads or at another time of the year. It is noteworthy that this figure of twentyfive family units/households is very similar to the paleodemographic estimates proposed for contemporary Bronze Age populations living in Arkhangaï (Houle 2010; cited in Houle 2017) or further north in the Hovsgol aimag (Frohlich et al. 2008). 
The Late Bronze Age is often presented as a period marked with major increases in people and animal mobility and our work also provides indirect insight into the question of the size of the regional networks at that time. Because animal remains were gradually deposited across a human lifetime around the khirgisuur, its construction did not require to draw on large regional networks and involve contributors from remote regions. Although this does not exclude the mobility of some individuals, our results suggest that the importance of local social and demographic organisation is perhaps underestimated. This is in partial disagreement with recent strontium isotopic evidence suggesting that Bronze Age horses from khirgisuurs located in the Khanuy Valley came from geographically distant locales and would be representative of social networks active over great distances (Makarewicz et al. 2018). More work based on the comparison of the isotopic signature of horse teeth with isotope mapping of the distribution of local bioavailable strontium will be required to fully address this question.

\section{Conclusion and perspective}

New radiocarbon dating, involving the excavation of a large number of structures and Bayesian modeling of the results allow, for the first time, a high precision chronology for the construction of a DSK complex to be derived. Our findings place the beginning of the construction of the B10 complex during the second half of the $11^{\text {th }} \mathrm{c}$. BCE. They do not plead in favor of a single ceremony for the building of these features as suggested by some authors (Fitzhugh \& Bayarsaikhan 2009; Fitzhugh 2017). They nevertheless strongly suggest that the time period required to construct the B10 complex was short, in the order of a human lifetime at the most. Bayesian modeling of the radiocarbon dates also demonstrated that ritual activities around the deer stones and the large khirgisuur complex are contemporary, highlighting a probable functional connection between the two types of monuments in agreement with (Fitzhugh 2009a; Taylor et al. 2017) contra (Jacobson-Tepfer 2001). This work highlights the importance of large monuments as structuring elements of Bronze Age societies, at a time of intense socio-political transformations of a scope hardly before seen in this region of Eastern Eurasia.

This work has also broader implications as it invites us to question the validity of previous chronologies proposed for the monumental cultures of central Asia based on the direct dating of bone collagen artifacts. Previous dates obtained at Tsatsyn Ereg have been 
shown to be completely unreliable. To a lesser extent, some of the new bone collagen dates presented here were also affected by contamination with modern carbon from the soil and required in-depth screening. We cannot dismiss the possibility that the contamination issue highlighted in this study could also apply to other sites where dated artifacts are heavily exposed to weathering. This would affect mostly shallowly buried finds like bones found in Bronze Age satellite features. In our study, contamination affected mostly bone but some teeth were also impacted. Only a careful selection under the microscope of the best preserved dentine and root fragment allowed to improve the collagen yield, $\mathrm{C} / \mathrm{N}$ ratio and ultimately the radiocarbon results. Because most of the available radiocarbon dates published for the Mongolian Bronze Age lack QC information, their overall reliability should be reassessed. We call for a widespread emulation of similar quality control measures in shallow burial contexts from across the Eurasian continent. As contamination adds modern carbon, making the dates look too young, this might bring into question earlier conclusions regarding the duration of the khirgisuur phenomenon, and the possible overlap with the slab-burial and the well-dated Arzhan culture in Mongolian Altai around 800 BCE (Taylor et al. 2017). Fully addressing these questions will require pursuing the research effort both in the field, with more in-depth excavation of key archaeological sites, and in the laboratory, by carefully selecting and directly dating the ritual structures implying domestic animals.

\section{Acknowledgments}

We thank all the members of the Monaco-Mongolia Archaeological Mission. We are particularly thankful to the members of the 2016 mission who excavated a large number of the dated structures. We thank D. Fiorillo (SSMIM, Paris), M. Massault (GEOPS, Orsay), C. Gauthier, N. Tisnérat and F. Thil (LSCE, Gif-sur-Yvette) for their help with isotopic analysis, graphitization and radiocarbon dating, respectively. We also thank J. Cucchi for English editing, R. Witcher and the two anonymous reviewers for insightful comments. Fieldwork was supported by the Monaco-Mongolia Archaeological Mission (dir. J. Magail) and the French archaeological mission in Mongolia (CNRS, MNHN, MAEDI, dir. S. Lepetz). The analyses were supported by the LabEx BCDiv and the CNRS.

\section{Reference list}

Allard, F. \& D. ERdenebaAtar. 2005. Khirigsuurs, ritual and mobility in the Bronze Age of Mongolia. Antiquity 79: 547-63. 
Allard, F., D. ERdenebaAtar. \& J.-L. Houle. Recent archaeological Research in the Khanuy River Valley, Central Mongolia, in Beyond the Steppe and the Sown: Proceedings of the 2002 University of Chicago Conference on Eurasian Archaeology, Brill Academic Publisher: 202-24. Colloquia Pontica Monograph Supplement of Ancient West \& East. Leiden: David L. Peterson, L.M. Popova, A.T. Smith.

Amartuvshin, C. 2007. Archaeology and Cultural Resource Management in Mongolia 20032007: a report from the preservation Sector. Ulaanbaatar. Mongolian Academy of Science, Institute of Archaeology.

Ambrose, S.H. 1990. Preparation and characterization of bone and tooth collagen for isotopic analysis Journal of Archaeological Science 17: 431-51.

BAYLISS, A. 2007. Bayesian Buildings: An Introduction for the Numerically Challenged Vernacular Architecture 38: 75-86.

Brock, F., T. Higham. \& C.B. RAMSEY. 2010. Pre-screening techniques for identification of samples suitable for radiocarbon dating of poorly preserved bones Journal of Archaeological Science 37: 855-65.

BRONK RAMSEY, C. 2009. Dealing with Outliers and Offsets in Radiocarbon Dating Radiocarbon 51: 1023-45. Cambridge Core.

Bronk-RAmSeY, C. \& S. LeE. 2013. Recent and Planned Developments of the Program OxCal Radiocarbon 55: 720-30.

Chatters, J.C., J.W. Brown., S. Hackenberger., P. McCutcheon. \& J. Adler. 2017. CALCINED BONE AS A RELIABLE MEDIUM FOR RADIOCARBON DATING: A TEST USING PAIRED NORTH AMERICAN SAMPLES American Antiquity 82: 593-608. Cambridge Core.

DENIRO, M.J. 1985. Postmortem preservation and alteration of in vivo bone collagen isotope ratios in relation to palaeodietary reconstruction Nature 317: 806-9.

ERdenebaAtAR, D. 2000. Burial materials related to the history of the Bronze Age on the territory of Mongolia, in Metallurgy in ancient Eastern Eurasia from the Urals to the Yellow River: 189-221. Linduff, K. M.

FiTZHUGH, W. 2009a. The mongolian deer stone-khirigsuur complex : dating and organisation of a late bronze age Menagerie, in Current Archaeological Research in Mongolia: 183-99. Department of Anthropology Staff Publications.

- 2009b. Pre-Scythian Ceremonialism, Deer Stone Art, and Cultural Intensification in Northern Mongolia, in B. Hanks \& K. Linduff (ed.) Social Complexity in Prehistoric Eurasia: Monuments, Metals and Mobility: 378-412. Cambridge: Cambridge University Press. https://www.cambridge.org/core/books/social-complexity-inprehistoric-eurasia/prescythian-ceremonialism-deer-stone-art-and-culturalintensification-in-northern-mongolia/9D726C82EBC248A68E709BE9D0B1B32F.

- 2017. Mongolian Deer Stones, European Menhirs, and Canadian Arctic Inuksuit: Collective Memory and the Function of Northern Monument Traditions Journal of Archaeological Method and Theory 24: 149-87.

Fitzhugh, W. \& J. BAYARSAikHAN. 2009. American-Mongolian Deer Stone Project: Field Report 2009. Arctic Studies Center. Washington, DC: Smithsonian Institution.

Frohlich, B., T. Amgalantugs., J. Littleton., D. Hunt., T. Frohlich. \& K. Goler. 2008. Bronze age burial mounds (khirigsuurs) in the Khovsgol aimag, Mongolia: a reconstruction of biological and social histories. Studia Archaeologica Instituti Academiae Scientarum Mongolicae. Ulaanbataar, Mongolia.

GANTULGA, J.-O. 2015. Recherches sur les monuments funéraires des nomades de l'Age du bronze et du début de l'Age du fer en Mongolie. Thèse de Doctorat de l'Université de Bourgogne - Franche Comté. 
Higham, T.G., R.M. JACOBI. \& C.B. RAMSEY. 2006. AMS radiocarbon dating of ancient bone using ultrafiltration Radiocarbon 48: 179-95.

Honeychurch, W., J. Wright. \& C. AMARTUVShin. 2009. Re-Writing Monumental Landscapes as Inner Asian Political Process, in Monuments, Metals, and Mobility: Trajectories of Complexity in the Late Prehistory of the Eurasian Steppe, B. Hanks, K. Linduff: 330-57. Cambridge: Cambridge University Press.

Houle, J.-L. 2009. Socially Integrative Facilities and the Emergence of Societal Complexity on the Mongolian Steppe, in B.K. Hanks \& K.M. Linduff (ed.) Social Complexity in Prehistoric Eurasia: Monuments, Metals and Mobility: 358-77. Cambridge: Cambridge University Press. https://www.cambridge.org/core/books/socialcomplexity-in-prehistoric-eurasia/socially-integrative-facilities-and-the-emergence-ofsocietal-complexity-on-the-mongoliansteppe/2F199BFD38A41FD65EB4EFDD385554EB.

- 2010. Emergent complexity on the Mongolian steppe: Mobility, territoriality, and the development of early nomadic polities. University of Pittsburgh. http://www.academia.edu/download/34885023/Houle_etd2010.pdf.

- 2017. Long-term occupation and seasonal mobility in Mongolia: a comparative study of two mobile pastoralist comunities, in Fitful Histories and Unruly Publics: Rethinking Temporality and Community in Eurasian Archaeology, Brill: 155-74. Leiden, The Netherland: Kathryn O. Weber Emma Hite Lori Khatchadourian Adam T. Smith.

JACOBSON-TEPFER, E. 2001. Cultural riddles: Stylized deer and deer stones of the Mongolian Altai Bulletin of Asian Institute 15: 31-56.

Lanting, J.N., A.T. Aerts-Bijma. \& J. VAn DER Plicht. 2001. Dating of Cremated Bones Radiocarbon 43: 249-54. Cambridge Core.

MAGAIL, J. 2008a. Tsatsiin Ereg, site majeur du début du Ier millénaire en Mongolie Bulletin d'anthropologie préhistorique de Monaco 48.

— 2008b. Tsatsiin Ereg, site majeur du début du Ier millénaire en Mongolie Bulletin d'anthropologie préhistorique de Monaco 48: 107-20.

— 2015. Les stèles ornées de Mongolie dites «pierres à cerfs », de la fin de l'âge du Bronze, in Statues-menhirs et pierres levées du Néolithique à aujourd'hui, Direction régionale des affaires culturelles Languedoc-Roussillon Groupe Archéologique du Saint-Ponais: 89-101. Gabriel Rodriguez et Henri Marchesi.

Makarewicz, C.A., C. Winter-SchuH., H. Byerly. \& J.-L. Houle. 2018. Isotopic evidence for ceremonial provisioning of Late Bronze age khirigsuurs with horses from diverse geographic locales Quaternary International. https://www.sciencedirect.com/science/article/pii/S104061821730455X.

Marchina, C., S. Lepetz., J. Magail. \& C. Salicis. 2017. The skull on the hill. Anthropological and osteological study of horse skull repositories among contemporary herders in Mongolia (Arkhangai province) Anthropozoologica 53: 17183.

TAYLOR, W. 2017. Horse demography and use in Bronze Age Mongolia Quaternary International 436: 270-82.

TaYlor, W., B. Jargalan., K. Lowry., J. Clark., T. Tuvshinjargal. \& J. BAYARSAIKHAN. 2017. A Bayesian chronology for early domestic horse use in the Eastern Steppe Journal of Archaeological Science 81: 49-58.

VAN KLINKEN, G.J. 1999. Bone Collagen Quality Indicators for Palaeodietary and Radiocarbon Measurements Journal of Archaeological Science 26: 687-95.

Volkov, V.V. 2002. Olennye Kamni Mongolii, 2nd edition. Academy of Sciences, Moscow. Nauka, Ulaanbaatar. 
WRIGHT, J. 2014. Landscapes of Inequality? A Critique of Monumental Hierarchy in the Mongolian Bronze Age Asian Perspectives 51: 139-63.

\section{Figure Legends:}

Fig. 1. Localization map of Tsatsyn Ereg and of the three dated monuments

Fig. 2. The large khirgisuur B10 at Tsatsyn Ereg, Mongolia.

Fig. 3. Plan of the khirgisuur KTS01 and the excavated peripheric structures

Fig. 4. Plan of the deer stone PAC 38 and the excavated peripheric structures

Fig. 5. Plan of the khirgisuur B10 and the excavated peripheric structures

Fig. 6. Ritual features at the B10 khirgisuur. Top panel: Mound ST 1 containing at its center the heads of two horses. Bottom panel: Circle ST 114 containing at its center (whitish area) calcined bones of caprines.

Fig. 7. Modeled start and end dates for the large khirgisuur B10, the deer stone PAC38 and the small khirgisuur KTS01 from the site of Tsatsyn Ereg.

Fig. 8. Modeled span for the large khirgisuur B10.

Fig. 9. Modeled spans for Model 0 (a) Model 50 (b) and Model 100 (c). The calibrated dates have been simulated from 50 samples which either all date to $1000 \mathrm{cal}$ BC (Model 0), or range from 1025 to $975 \mathrm{cal} \mathrm{BC}$ (Model 50), or range from 1050 to $950 \mathrm{cal} \mathrm{BC}$ (Model 100). 


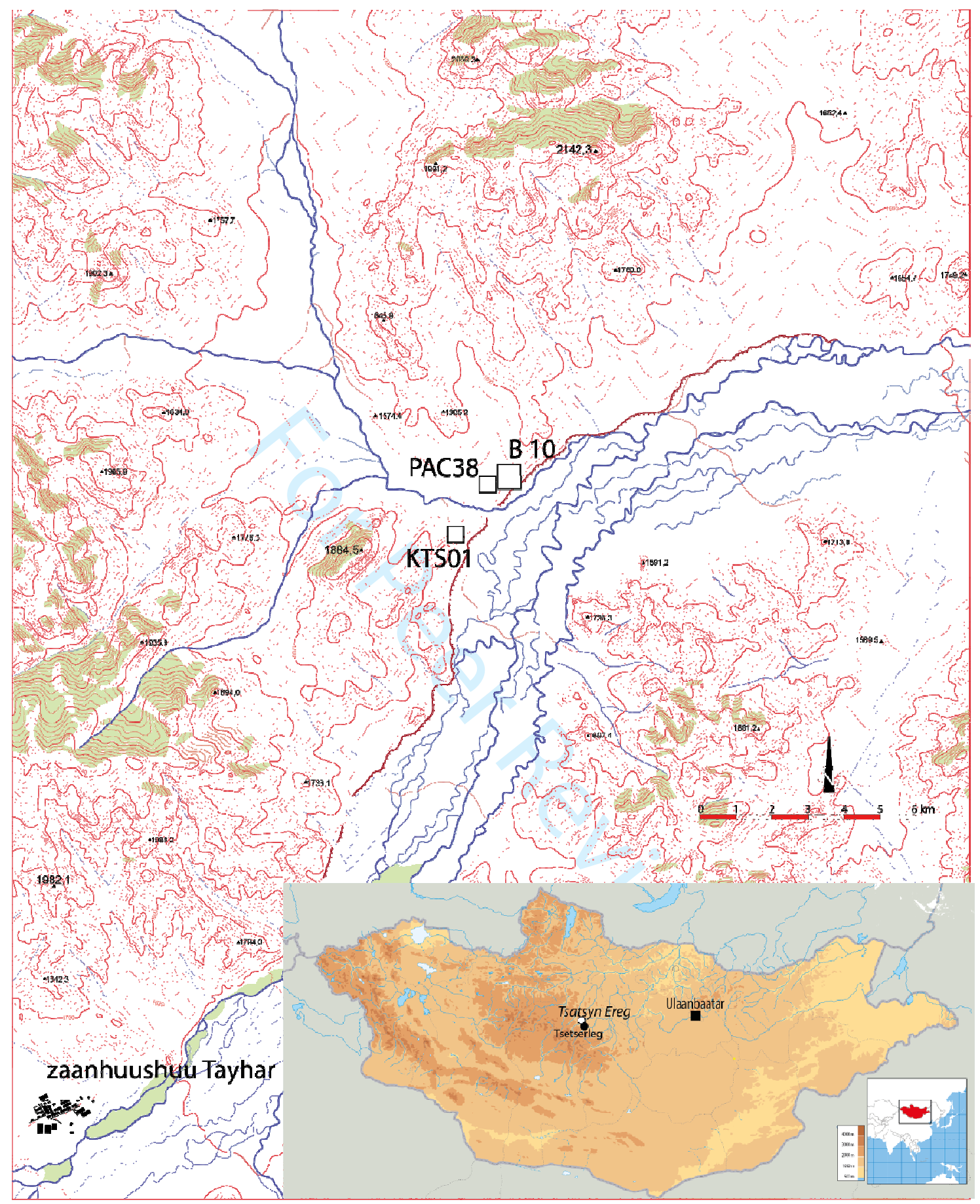

Fig. 1. 


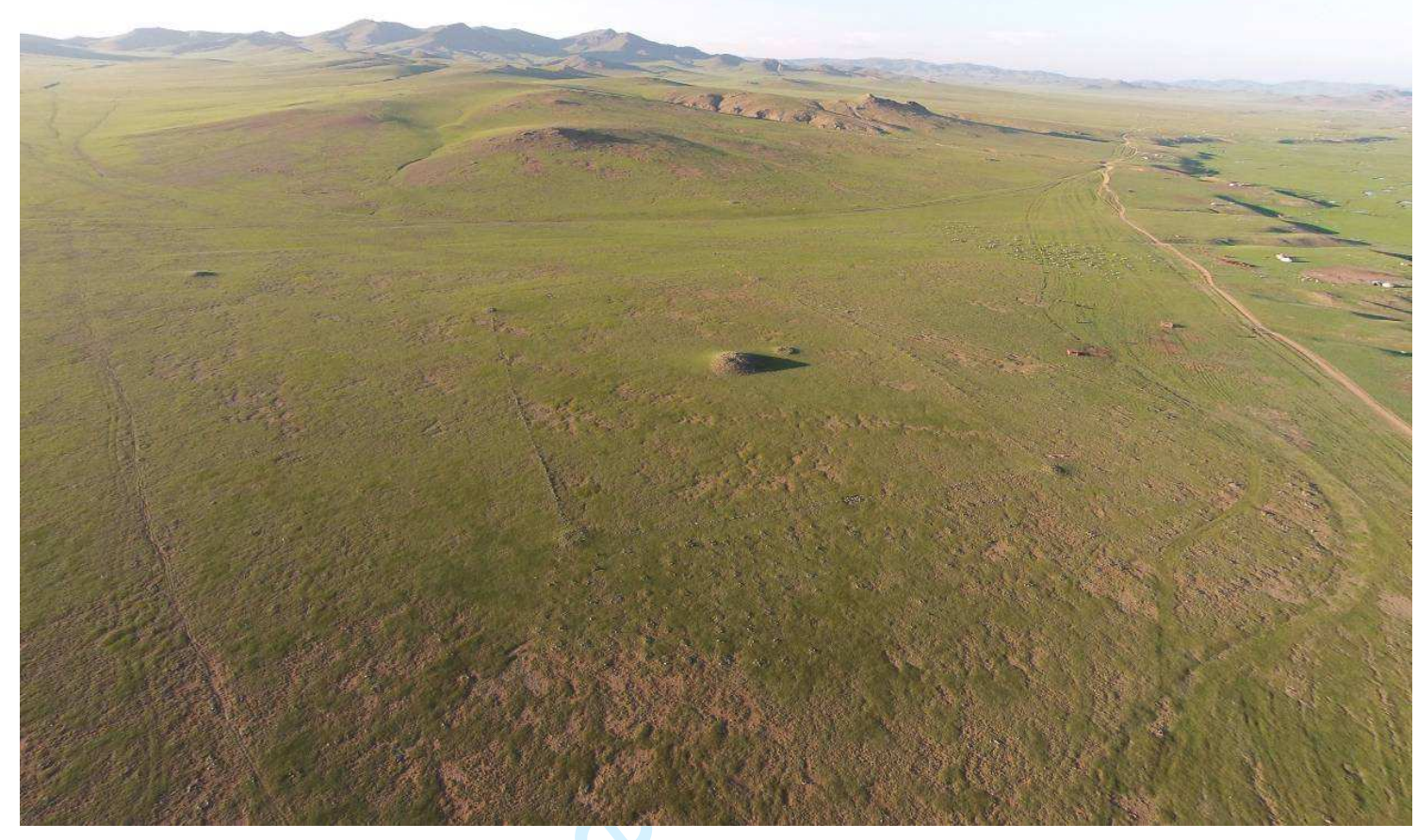

Fig. 2. 

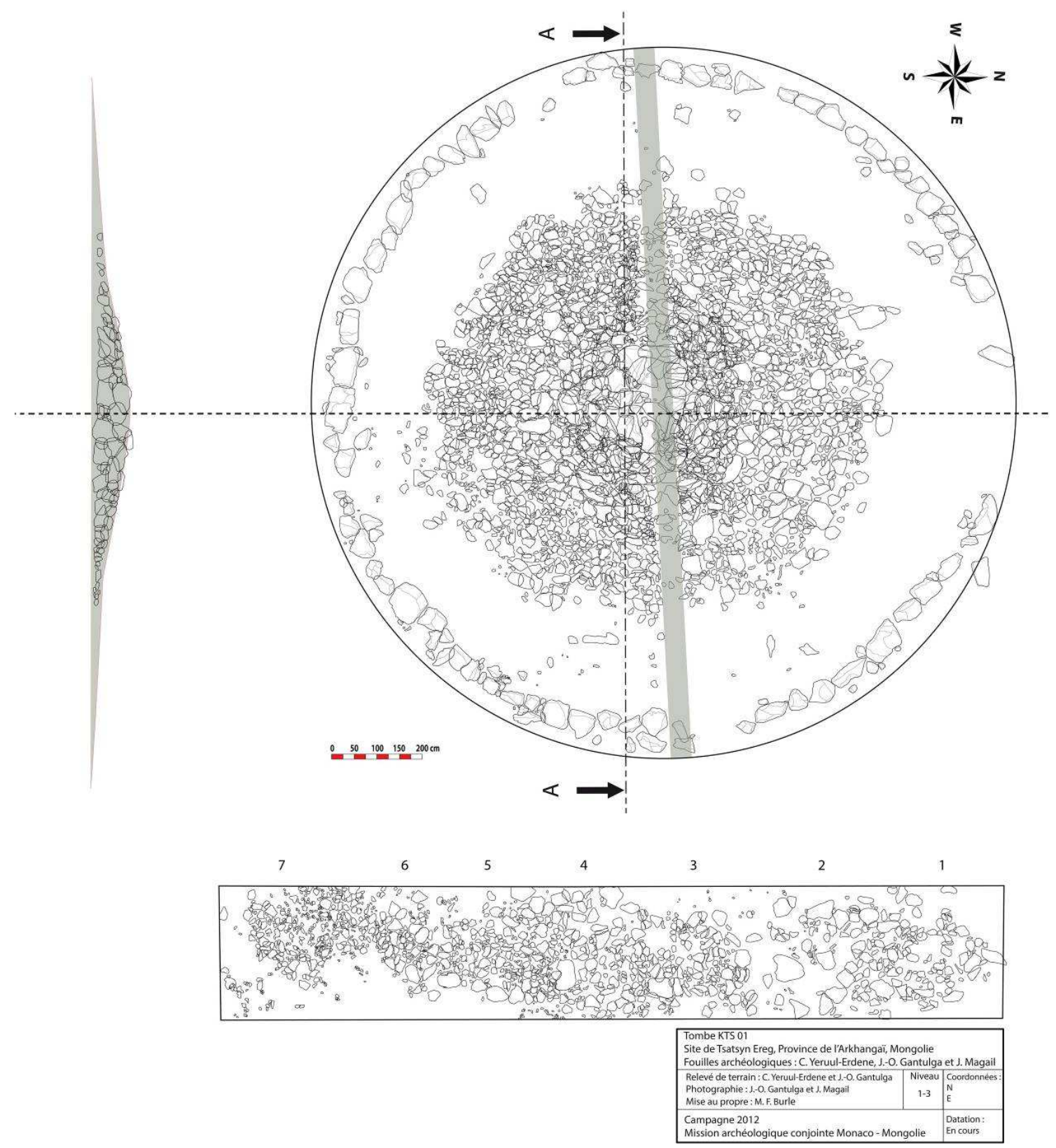

Fig. 3. 


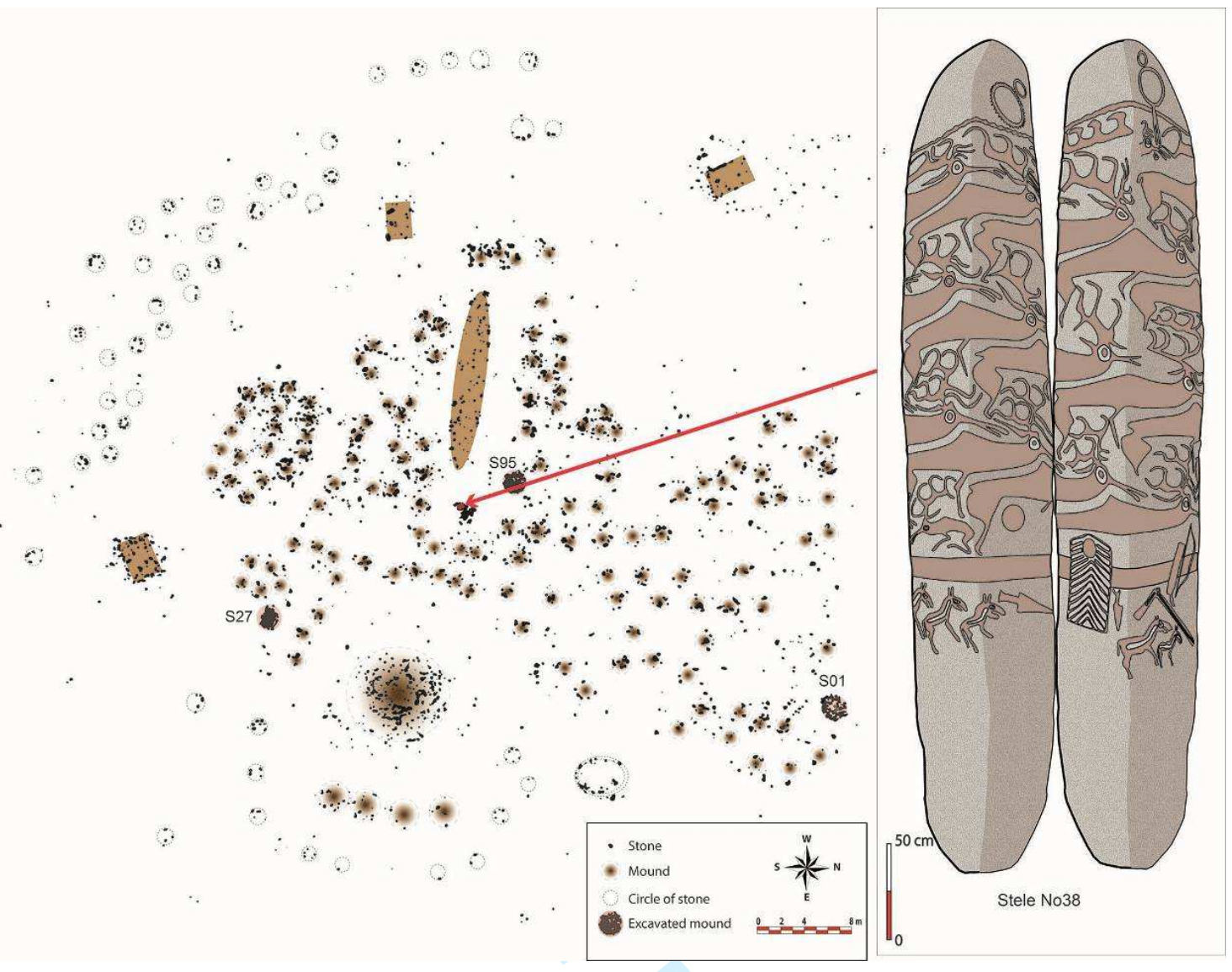

Fig. 4. 


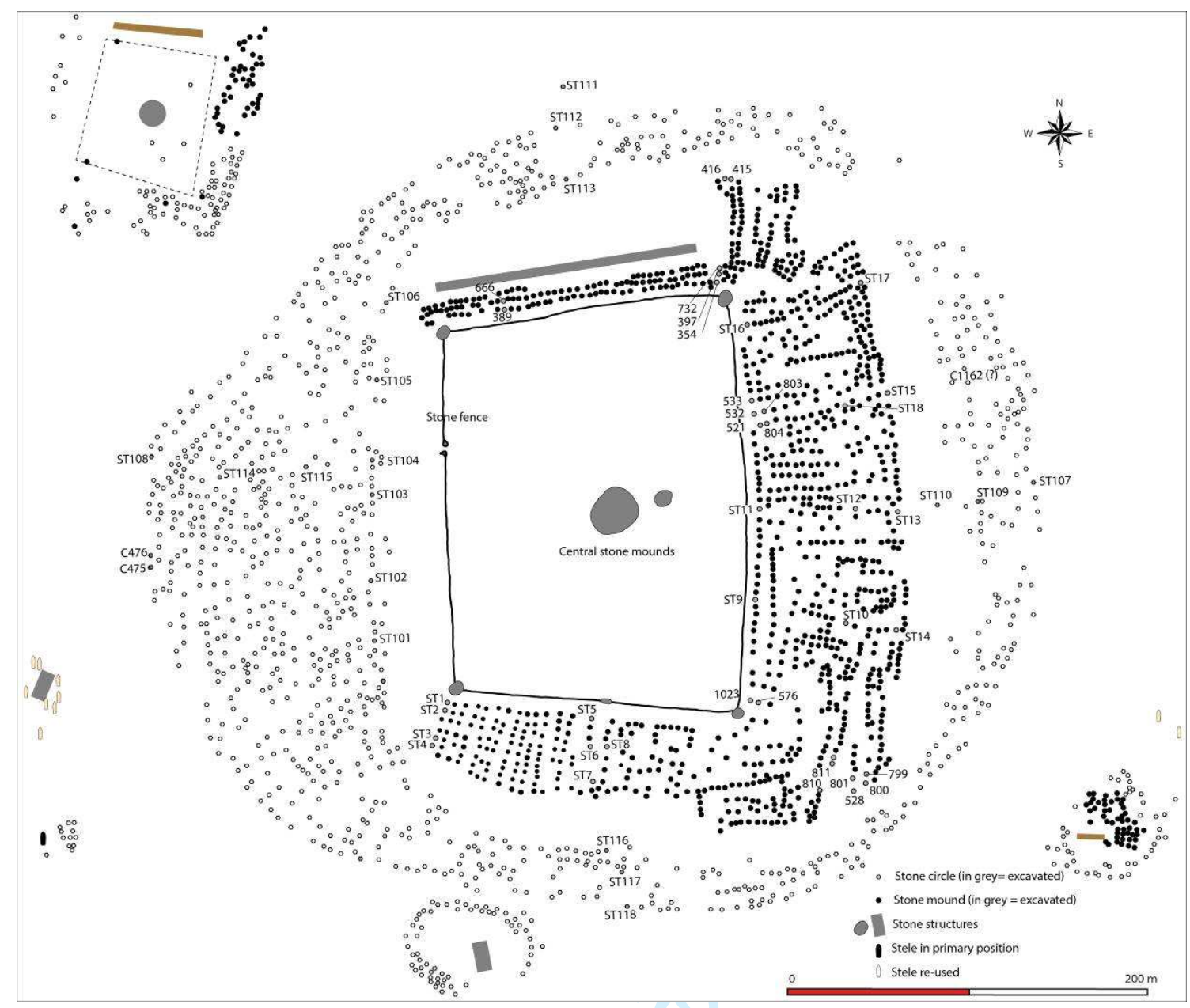

Fig. 5. 

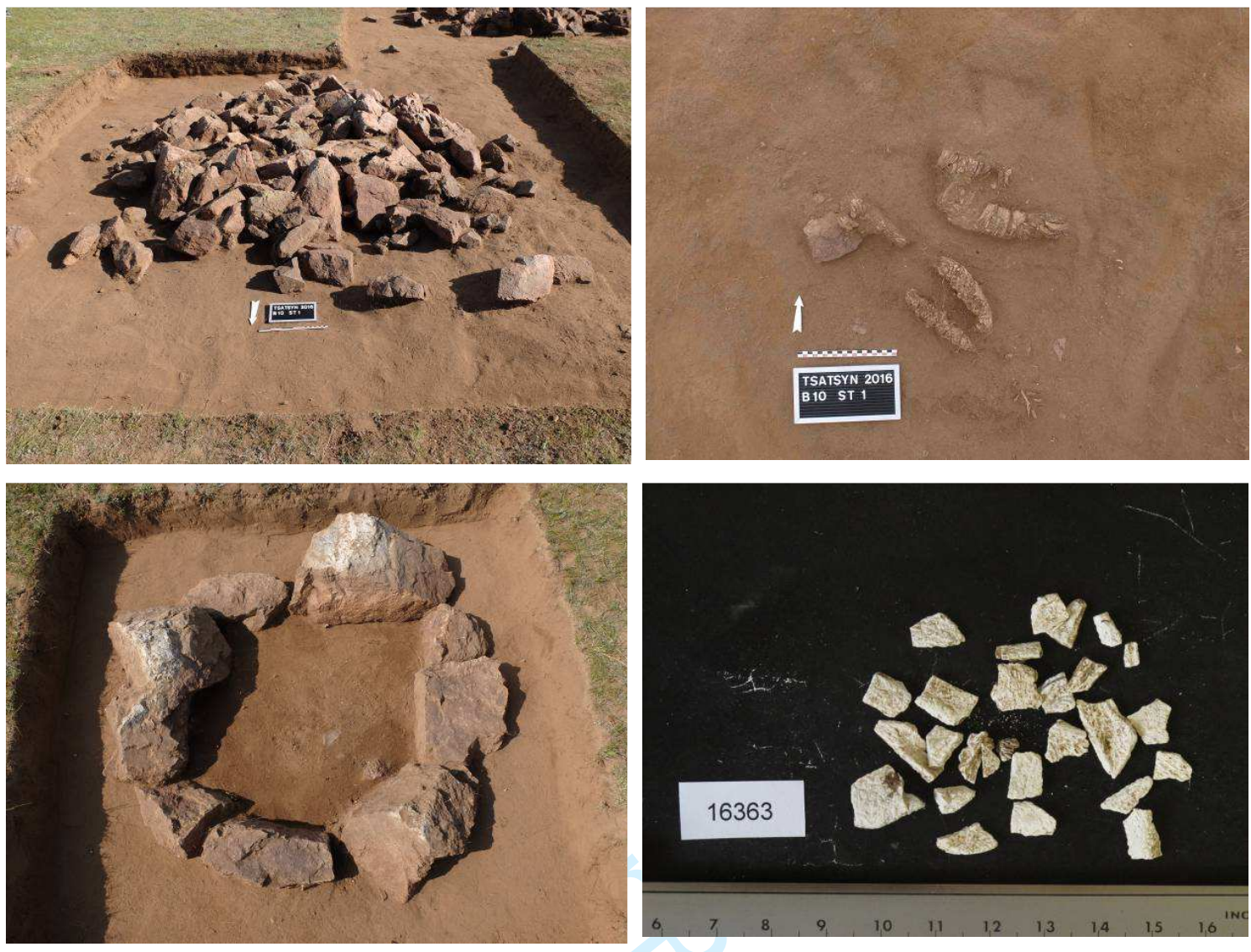

Fig. 6.

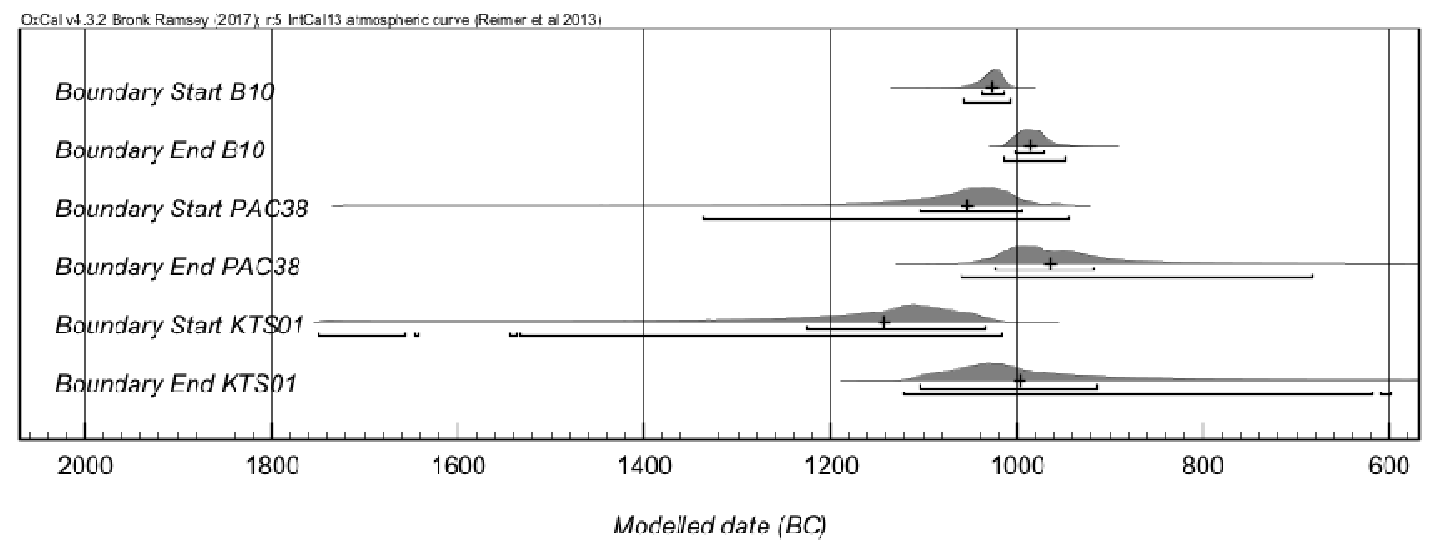

Fig. 7. 


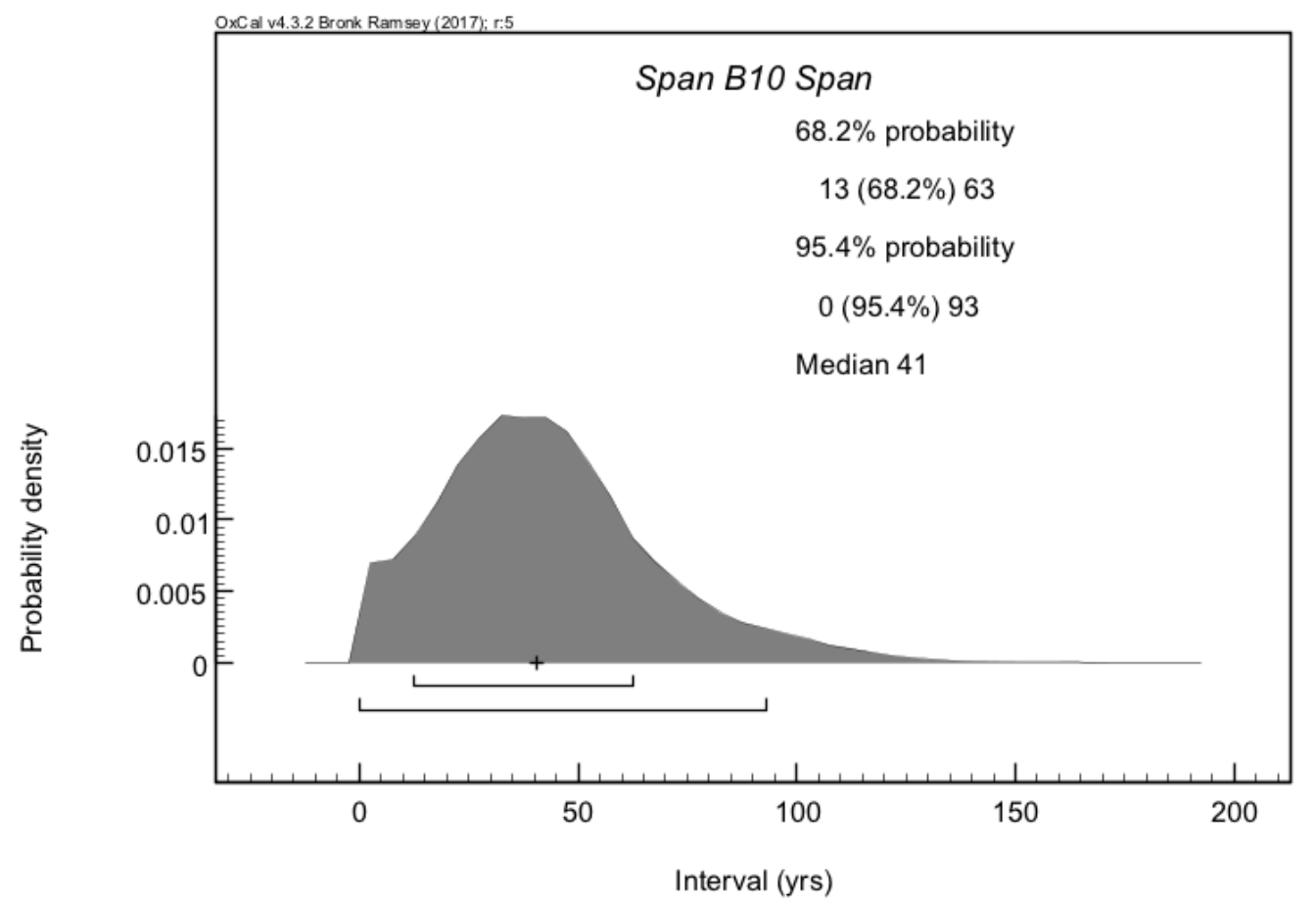

Fig. 8. 


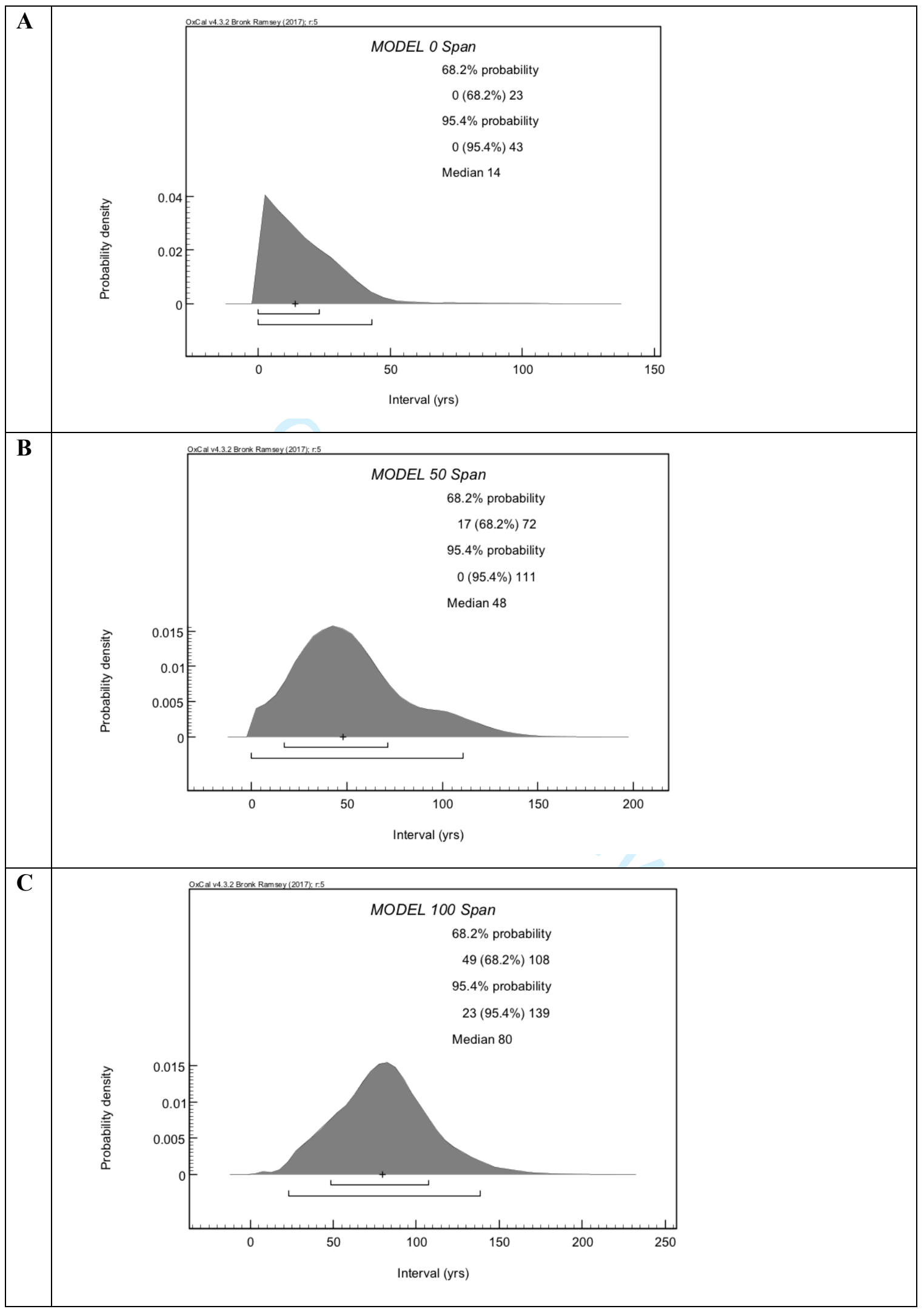

Fig. 9. 
Table 1. Results of the Tsatsyn Phase Model using the IntCal13 calibration curve

\begin{tabular}{|c|c|c|c|c|c|c|}
\hline \multirow[b]{3}{*}{ Boundary } & \multicolumn{6}{|c|}{ IntCal 13} \\
\hline & \multirow{2}{*}{$\begin{array}{c}\text { Number of } \\
\text { dates in the } \\
\text { Model }\end{array}$} & \multicolumn{2}{|c|}{$68.2 \%$ (y cal BCE) } & \multicolumn{2}{|c|}{95.4 (y cal BCE) } & \multirow[b]{2}{*}{ Median } \\
\hline & & From & To & From & To & \\
\hline \multicolumn{7}{|l|}{ B10 } \\
\hline Start & 57 & -1037 & -1014 & -1057 & -1007 & -1027 \\
\hline End & & -1003 & -972 & -1014 & -948 & -986 \\
\hline Span & & 13 & 63 & 0 & 93 & 41 \\
\hline \multicolumn{7}{|l|}{ PAC38 } \\
\hline Start & 3 & -1104 & -996 & -1337 & -945 & -1054 \\
\hline End & & -1024 & -919 & -1060 & -684 & -965 \\
\hline Span & & 0 & 53 & 0 & 113 & 32 \\
\hline \multicolumn{7}{|l|}{ KTS01 } \\
\hline Start & 2 & -1226 & -1034 & -1749 & -1017 & -1143 \\
\hline End & & -1106 & -914 & -1122 & -379 & -998 \\
\hline Span & & 0 & 42 & 0 & 103 & 22 \\
\hline
\end{tabular}

Results obtained using the Outlier approach 
Table 2. Probability that the start of Event 1 (left column) precedes Event 2 (top row) using OxCal 'Order' function

\begin{tabular}{|c|c|c|c|c|}
\hline & & \multicolumn{3}{|l|}{ Event 2} \\
\hline & & B10 & PAC38 & KTS01 \\
\hline \multirow[t]{3}{*}{ Event 1} & B10 & - & $27.73 \%$ & $1.76 \%$ \\
\hline & PAC38 & $72.27 \%$ & - & $20.16 \%$ \\
\hline & KTS01 & $98.24 \%$ & $79.84 \%$ & - \\
\hline
\end{tabular}


Table 3. Results of the Model 0, 50 and 100 using the IntCal13 calibration curve

\begin{tabular}{|c|c|c|c|c|c|c|}
\hline \multirow[b]{3}{*}{ Boundary } & \multicolumn{6}{|c|}{ IntCal 13} \\
\hline & \multirow{2}{*}{$\begin{array}{c}\text { Number of } \\
\text { dates in the } \\
\text { Model }\end{array}$} & \multicolumn{2}{|c|}{$68.2 \%$ (y cal BCE) } & \multicolumn{2}{|c|}{95.4 (y cal BCE) } & \multirow[b]{2}{*}{ Mediar } \\
\hline & & From & To & From & To & \\
\hline \multicolumn{7}{|l|}{ Model 0} \\
\hline Start & 50 & -1014 & -1001 & -1024 & -988 & -1007 \\
\hline End & & -1003 & -981 & -1006 & -969 & -991 \\
\hline Span & & 0 & 23 & 0 & 42 & 14 \\
\hline \multicolumn{7}{|l|}{ Model 50} \\
\hline Start & 50 & -1042 & -1013 & -1059 & -1006 & -1029 \\
\hline End & & -999 & -966 & -1006 & -934 & -979 \\
\hline Span & & 17 & 72 & 0 & 111 & 48 \\
\hline \multicolumn{7}{|l|}{ Model 100} \\
\hline Start & 50 & -1060 & -1031 & -1077 & -1017 & -1046 \\
\hline End & & -985 & -946 & -996 & -926 & -964 \\
\hline Span & & 49 & 108 & 23 & 139 & 80 \\
\hline
\end{tabular}




\section{Supporting Information}

\section{Table of contents}

\section{S.1. Previous radiocarbon dating of Urt Bulagyn (Khanuy Valley) and the Tsatsyn Ereg monuments (Khoid Tamir Valley) discussed in this paper}

\section{S.2. Methods}

\section{S 3. Results}

\section{S.4. Modeling}

\section{Tables and Figures}

Table S1. Previous radiocarbon dates from Urt Bulagyn (Khanuy Valley, Arkhangaï aimag) the B10 complex and deer stone PAC 38 (Khoid Tamir Valley, Arkhangaï aimag)

Table S2. Results of the 100 AMS-radiocarbon analyses performed on charcoal (7), calcined bone (20) and bone and tooth collagen (73) from the B10 complex, the deer stone PAC38, and the khirgisuur KTS01.

Figure S1. Previous calibrated dates from Urt Bulagyn (Khanuy Valley) and the Khoid Tamir Valley monuments discussed in this paper (see Table S1 for details)

Figure S2. Left panel: comparison of radiocarbon dates of charcoal and calcined bones in six circles from the B10 complex. Right panel: radiocarbon age (average $\pm S D, n=6$ ) for charcoal (black circle) and calcined bone (open circle).

Figure S3. Top panel: relationship between bone and tooth collagen radiocarbon age and $\mathrm{C} / \mathrm{N}$ ratio at KTS01. Bottom panel: relationship between bone and tooth collagen radiocarbon age and collagen yield at KTS01. Collagen was extracted using Method 1.

Figure S4. Top panel: relationship between bone and tooth collagen radiocarbon age and $\mathrm{C} / \mathrm{N}$ ratio at the B10 complex. Bottom panel: relationship between bone and tooth collagen radiocarbon age and yield at the B10 complex. Collagen was extracted using Method 1.

Figure S5. Top panel: comparison of radiocarbon dates of high molecular weight (HMW, > 30KDa) and low molecular weight (LMW, $<30 \mathrm{KDa}$ ) fractions of six ultrafiltered collagen samples prepared using Method 2 (see Table S2 for details). Bottom panel: comparison of $\mathrm{C} / \mathrm{N}$ ratios of high molecular weight (HMW, $>30 \mathrm{KDa})$ and low molecular weight $(\mathrm{LMW},<30 \mathrm{KDa})$ fractions of six ultrafiltered collagen samples prepared using Method 2.

Figure S6. Left panel: Comparison of radiocarbon dates of collagen samples prepared using Method 1 (no ultrafiltration) and Method 2 (ultrafiltration, HMW fraction). Right panel: Radiocarbon age (average $\pm \mathrm{SD}, \mathrm{n}=15$ ) for each method. 


\section{S1 Previous radiocarbon dating of Urt Bulagyn (Khanuy Valley) and the Tsatsyn Ereg monuments (Khoid Tamir Valley) discussed in this paper}

To date, only two large khirgisuurs have multiple dates: Urt Bulagyn and the B10 complex both located in central Mongolia (Arkhangaï aimag). Urt Bulagyn (Khanuy Valley) covers about 15 ha and contains ca. 2700 peripheric structures out of which only four have been excavated and dated (Allard \& Erdenebaatar 2005; Fitzhugh \& Bayarsaikhan 2009). The calibrated dates suggest a possible outward growth for the satellite mound sector over a period of a few hundred years between the $11^{\text {th }}$ and the $7^{\text {th }} \mathrm{c} \mathrm{BCE}$ (Table S1 Fig S1). The DSK complex of Tsatsyn Ereg is located $50 \mathrm{~km}$ southeast of Urt Bulagyn in the Khoid Tamir Valley. It contains several deer stones and a large khirgisuur (B10) covering about 22 ha and containing 2361 peripheral structures (Magail 2008). This monument is part of the area surveyed and excavated since 2007 by the Monaco-Mongolia mission in Mongolia under the patronage of H.S.H. Prince Albert II and the aegis of UNESCO. Two mounds associated with a deer stone (PAC38) were dated and returned ${ }^{14} \mathrm{C}$ ages of $2580 \pm 30$ and $2660 \pm 30 \mathrm{BP}$, covering a period comprised between the $9^{\text {th }}$ and the $6^{\text {th }} \mathrm{c}$. BCE (Gantulga 2015). The dates obtained on six peripheral structures associated with the B10 complex vary between $2160 \pm 30$ $\mathrm{BP}$ and $2800 \pm 30 \mathrm{BP}$ (Table S1, Figure S1). The calcined bones found in the circles returned the oldest ages. Two mounds (532 and 803) contained two horse heads each, which were both dated yet which returned very different ${ }^{14} \mathrm{C}$ ages (Table S1, Figure S1). The results obtained at Tsatsyn Ereg are somewhat problematic for several reasons. First, they could suggest that circles from the B10 complex were constructed several centuries before the mounds. This is rather counter intuitive from a geometric point of view since the circles surround the mounds and form the outer ring of the structure. Second, the age difference between the two individual horses found in the same mound is difficult to explain. This result would suggest either two distinct interventions in a single mound separated by several centuries, or the deposition of a weathered horse skull together with a freshly killed horse head, something undocumented archaeologically. Finally, the wide large age range would argue for an extensive period of use for this khirgisuur from about the $11-10^{\text {th }} \mathrm{c}$ BCE to the $4-2^{\text {nd }} \mathrm{c}$. BCE. If confirmed, the prevalence of the same ceremonial activity over several centuries would be unprecedented archaeologically and raise questions regarding its significance and function.

For the reasons mentioned above, we consider it likely that serious doubts must be attached to the vast majority of the radiocarbon dates performed at Tsatsyn Ereg. The collagen dates in particular seemed doubtful and invite us to revisit the dating of the site. Collagen is usually considered the material of choice for radiocarbon dating as it allows direct dating of the bone remains. The chemical integrity of the molecule can be assessed independently of the measured age, using collagen yield and C/N ratio as proxies (DeNiro 1985; Ambrose 1990; van Klinken 1999). The vast majority of the samples dated in Mongolia, including the ones mentioned above (but see (Taylor et al. 2017)), were processed by Beta Analytics, a private company which provides very little detail about its analytical procedures and which did not include, until very recently, the classical quality control indicators of collagen yield and $\mathrm{C} / \mathrm{N}$ ratio. 
Table S1. Previous radiocarbon dates from Urt Bulagyn (Khanuy Valley, Arkhangaï aimag) the B10 complex and deer stone PAC 38 (Khoid Tamir Valley, Arkhangaï aimag)

\begin{tabular}{|c|c|c|c|c|c|c|c|c|c|}
\hline \multirow[t]{2}{*}{ Structure type } & \multirow[t]{2}{*}{ Feature } & \multirow[t]{2}{*}{ Sample material } & \multirow[t]{2}{*}{ Sample detail } & \multirow[t]{2}{*}{ Target \# } & \multirow[t]{2}{*}{${ }^{14} \mathrm{C}$ age } & \multirow[t]{2}{*}{ error } & \multicolumn{2}{|c|}{ 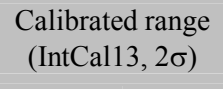 } & \multirow[t]{2}{*}{ Reference } \\
\hline & & & & & & & From & To & \\
\hline \multicolumn{10}{|c|}{ Khirgisuur B10 (Khoid Tamir Valley) } \\
\hline \multirow{3}{*}{ Circles } & C531 & calcined bone & - & B-290938 & 2790 & 30 & -1011 & -846 & Gantulga 2015 \\
\hline & C531 & calcined bone & . & B-290945 & 2760 & 30 & -992 & -830 & Gantulga 2015 \\
\hline & C1162 & calcined bone & - & B-290943 & 2800 & 30 & -1027 & -848 & Gantulga 2015 \\
\hline \multirow{6}{*}{ Mounds } & SAT 528 & indet. & 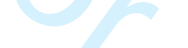 & B-323801 & 2590 & 30 & -820 & -595 & Gantulga 2015 \\
\hline & SAT 532 & bone fragment & Horse B & B-290941 & 2270 & 40 & -403 & -206 & Gantulga 2015 \\
\hline & SAT 532 & tooth fragment & Horse A & B-290940 & 2610 & 40 & -894 & -590 & Gantulga 2015 \\
\hline & SAT 803 & bone fragment & Horse B & B-290936 & 2160 & 30 & -358 & -108 & Gantulga 2015 \\
\hline & SAT 803 & petrous bone & Horse A & B-290935 & 2310 & 40 & -482 & -209 & Gantulga 2015 \\
\hline & SAT 811 & indet. & & B-323804 & 2340 & 30 & -507 & -366 & Gantulga 2015 \\
\hline \multicolumn{10}{|c|}{ Deer Stone PAC38 (Khoid Tamir Valley) } \\
\hline \multirow{2}{*}{ Mounds } & PAC38-1 & Horse bone & - & B-323806 & 2660 & 30 & -895 & -794 & Gantulga 2015 \\
\hline & PAC38-95 & Horse bone & - & B-323808 & 2580 & 30 & -814 & -590 & Gantulga 2015 \\
\hline \multicolumn{10}{|c|}{ Khirgisuur Urt Bulagyn (Khanuy Valley) } \\
\hline \multirow{4}{*}{ Mounds } & KYR1-9 & Horse tooth & - & B-159598 & 2810 & 40 & -1073 & -843 & Allard and Erdenebatar 2005 \\
\hline & KYR1-17 & Horse tooth & - & B-170749 & 2680 & 70 & -1015 & -597 & Allard and Erdenebatar 2005 \\
\hline & KYR1-21 & Horse tooth & - & B-222532 & 2780 & 50 & -1049 & -820 & Fitzhugh and Bayarsaikhan 2009 \\
\hline & KYR1-22 & Horse tooth & - & B-222533 & 2790 & 40 & -1042 & -836 & Fitzhugh and Bayarsaikhan 2009 \\
\hline
\end{tabular}


Figure S1. Previous calibrated dates from Urt Bulagyn (Khanuy Valley) and the Khoid Tamir Valley monuments discussed in this paper (see Table S1 for details)

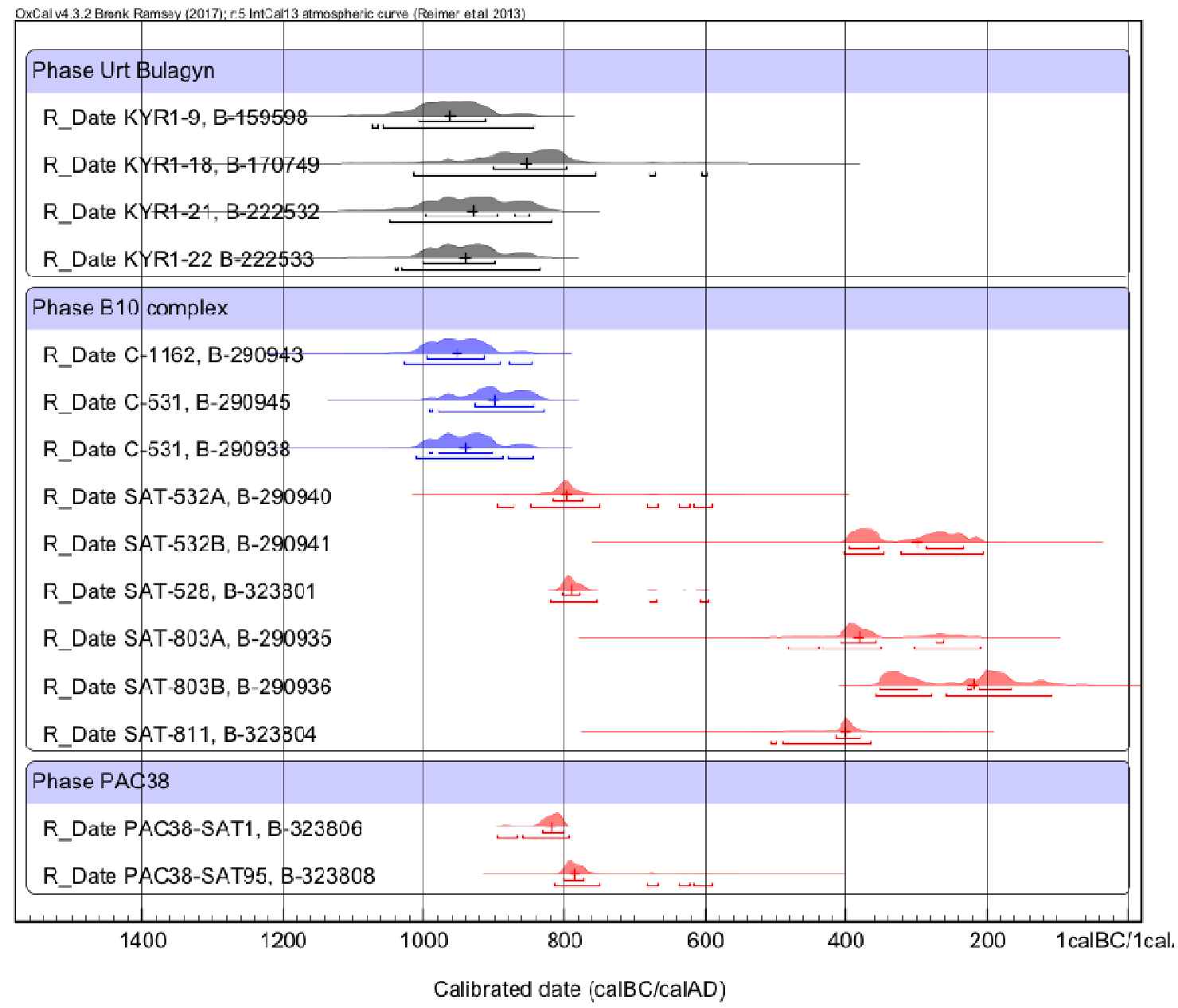




\section{S.2. Methods}

\section{Calcined bone}

Calcined bones were sonicated in distilled water and oven-dried. Only the whitest fragments were selected with 1-2 g being powdered $(<100 \mu \mathrm{m})$. The powder was then pretreated in acetic acid (1N) under a weak vacuum for $20 \mathrm{~h}$ to remove diagenetic carbonates, rinsed in distilled water and oven-dried. Yields were calculated and carbon isotope values were measured using a Kiel interfaced with a Thermo DeltaPlus Advantage mass spectrometer. All samples had $\delta^{13} \mathrm{C}$ values below $-20 \%$ indicating that recrystallization was complete (Zazzo et al. 2012; Hüls et al. 2010). A total of 0.5-1.0 g was hydrolyzed in orthophosphoric acid under a vacuum for $20 \mathrm{~min}$. The evolved CO2 was cleaned using Sulfix then introduced in a semiautomated graphitization unit.

\section{Charcoal}

Charcoal was pretreated using the classical acid-alkali-acid method. First immersed in $\mathrm{HCl}$ $1 \mathrm{~N}$ for $1 \mathrm{~h}$, rinsed to neutrality then immersed in $\mathrm{NaOH} 0.1 \mathrm{~N}$ for 1-20 min depending on the degree of decoloration, rinsed to neutrality, then immersed in $\mathrm{HCl} 1 \mathrm{~N}$ again for $1 \mathrm{~h}$. Finally, the samples were rinsed and oven-dried overnight at $50^{\circ} \mathrm{C}$. Yields were calculated and only samples with yields above 50\% were dated. These samples (1-3 mg) were then wrapped in ultra-light tin capsules, combusted and graphitized in the automated AGE 3 device.

\section{Bone and tooth collagen}

Each mound that provided a horse remain was sampled for radiocarbon dating. When two horses were deposited in the same mound, both were sampled. When possible, bone and teeth from the same individual were also sampled. We selected the petrous bone as this bone is considered to be denser and therefore the favorite support for DNA and collagen extraction (Pinhasi et al. 2015). Bone and teeth were rinsed in an ultrasonic bath then oven-dried overnight. They were crushed in a mortar and pestle, then sieved and the $0.3-0.7 \mathrm{~mm}$ fraction was kept for analysis. For teeth, we selectively removed the enamel and cement fractions under the microscope and only kept the better looking dentine and/or root fraction. Two methods of collagen extraction were used. The first method was our in-house protocol (Bocherens et al. 1991). Coarse bone powder (0.3-0.7 mm) was immersed in $1 \mathrm{~N} \mathrm{HCl}$ for 20 min under continuous stirring. The solution was filtered on a $5.0 \mu \mathrm{m}$ pore size mixed cellulose 
ester membrane, then rinsed. After which the acid insoluble residue was immersed in $0.1 \mathrm{~N}$ $\mathrm{NaOH}$ for $20 \mathrm{~h}$. The solution was then filtered again on the cellulose membrane and rinsed. The resulting alkali-insoluble residue was subsequently immersed in $0.01 \mathrm{~N} \mathrm{HCl}$ and gelatinized at $100{ }^{\circ} \mathrm{C}$ for $17 \mathrm{~h}$. The final solution was then filtered on the cellulose membrane and the gelatinized collagen freeze-dried. Most of the collagen samples had a creamy to beige color, suggesting incomplete decontamination. For eighteen samples, we added an ultrafiltration step to further purify the extracted collagen. The ultrafilters (Vivaspin ${ }^{\circledR} 15$ ) were cleaned following (Brock et al. 2013). The solubilized collagen was spun for $20 \mathrm{~min}$ at $3000 \mathrm{rpm}$ and the remaining volume was checked. This operation was repeated until only $0.5-$ $1 \mathrm{~mL}$ remained in the upper part of the filter. Both fractions were collected and freeze-dried. About $2.5 \mathrm{mg}$ of collagen was wrapped in an ultra-light tin capsule, and combusted in the elemental analyzer (EA) of an AGE 3 automated compact graphitization system (Wacker et al. 2010). The quality control parameters $(\% \mathrm{C}, \% \mathrm{~N}$ and $\mathrm{C} / \mathrm{N}$ ratios $)$ were measured in the $\mathrm{EA}$ prior to graphitization. The $\mathrm{CO} 2$ was then transferred to the graphitization unit where reduction was performed in seven quartz reactors, each containing $5 \mathrm{mg}$ of iron catalyst. In order to reduce the risk of memory effects in the graphite reactors, a sample of similar expected age (a VIRI F collagen sample of about $2525 \pm 69 \mathrm{BP}$, or an aliquot of the same sample) was combusted prior to each sample to be dated. Graphite samples were then pressed into targets within a few days. Two oxalic acid II standards and two phtalic anhydride blanks were processed together with the unknowns every ten samples (Synal et al. 2007). Graphite targets were dated using the compact AMS ECHoMICADAS at Gif-sur-Yvette (France). Data reduction was performed using BATS software (version 4.07)(Wacker et al. 2010). The first couple of scans were discarded to account for possible surface contamination of the target due to contact with ambient air between the graphitization and the AMS measurement. Measurement parameters such as $12 \mathrm{C}$ current and $13 \mathrm{CH}$ current were checked. Time and isobar corrections were made prior to validation. Normalization, correction for fractionation and background corrections were applied for each individual run by measuring the oxalic acid II NIST standard and the phthalic anhydride blanks. 


\section{S.3. Results}

\section{Radiocarbon dating of the circles}

Calcined bones and charcoal from twenty circles within the B10 complex were analyzed and the results are summarized in the SI Appendix (Table S2 and Fig. S2). Calcined bone $\delta^{13} \mathrm{C}$ values ranged between -19.7 and $-25.4 \%$ and are typical of well-calcined bones. Their radiocarbon age range was between $2770 \pm 20$ and $2860 \pm 20 \mathrm{BP}$ (average $2827 \pm 6 \mathrm{BP}, \mathrm{n}=20$ ). There was no correlation between calcined bone age and carbon isotope value, indicating that the bone samples had not been significantly affected by contamination from soil carbonate ( $\mathrm{r} 2=0.07)$. The charcoal radiocarbon age range was between $2780 \pm 20$ and $2910 \pm 25 \mathrm{BP}$ (average $2839 \pm 18 \mathrm{BP}, \mathrm{n}=7$ ). Overall, charcoal and calcined bone radiocarbon ages did not differ significantly (T-test, $\mathrm{p}=0.41$ ). In six circles, pairs of calcined bone and charcoal were dated (SI Appendix, Fig. S2). Four pairs of dates (circles C107, 111, 113 and 117) passed the Chi2 test $(\mathrm{T}<3.84)$, while the remaining two did not. In one case $(\mathrm{C} 103)$, charcoal was $75{ }^{14} \mathrm{C}$ years younger than the calcined bone, possibly suggesting possible contamination of the charcoal by roots; in the case of $\mathrm{C} 102$, the charcoal was $75{ }^{14} \mathrm{C}$ years older, possibly highlighting an old wood effect. For these six pairs, the ${ }^{14} \mathrm{C}$ dates from charcoal were more variable than from the calcined bones but the average values were not significantly different $(2840 \pm 53$ BP vs $2842 \pm 24$ BP, $n=15)(p=0.94)$.

\section{Radiocarbon dating of the mounds}

Collagen was extracted from the horse bones and teeth from the three excavated complexes: KTS-01, B10 and PAC38. The results are summarized in SI Appendix (Table S2). Because the chronological relationships between the three complexes cannot be assessed independently, the results are described separately. All the bones and teeth were treated using Method 1(Bocherens et al. 1991). For a subset of 18 samples the collagen underwent an extra step of ultrafiltration (Method 2). The results obtained using the two methods are presented below.

\section{Method 1}

Khirgisuur KTS-01: The seven mounds associated with the khirgisuur KTS-01 were excavated and six of them provided datable material. Collagen was extracted from four petrous bones and two teeth. Collagen contents ranged from 4.7 to $14.9 \%$, higher than the cutoff value of $1 \%$ used by radiocarbon labs (van Klinken 1999; Brock et al. 2010). Higher 
yields were measured in tooth samples (11.9 and 14.9\%) than in petrous bones $(4.7-8.7 \%)$. $\mathrm{C} / \mathrm{N}$ ratios ranged from 3.23 to 3.51, within the 2.9-3.6 range of uncontaminated collagen (DeNiro 1985; Ambrose 1990). C/N ratios were lower in teeth (3.23 and 3.24) than in bones (3.30-3.51). Radiocarbon ages ranged between 2785 and 2890 BP. A positive correlation was found between the collagen yield and the ${ }^{14} \mathrm{C}$ age $(\mathrm{r} 2=0.94)$, and a negative correlation was found between the $\mathrm{C} / \mathrm{N}$ ratio and the ${ }^{14} \mathrm{C}$ age $(\mathrm{r} 2=0.86)$ (SI Appendix, Fig. S3).

Deer stone PAC38: Three mounds associated with the deer stone PAC38 were excavated and collagen was extracted from three horse teeth. High collagen contents (15-16\%), and low $\mathrm{C} / \mathrm{N}$ ratios (3.21 to 3.24) were measured. The radiocarbon ages cluster tightly and range between 2840 and 2860 BP. No correlation was found between the collagen yield, the $\mathrm{C} / \mathrm{N}$ ratio and the ${ }^{14} \mathrm{C}$ age.

Khirgisuur B10: From the B10 complex, thirty out of the 38 excavated mounds provided datable material (either bones or teeth) which was sampled for radiocarbon dating. In some of the structures, both bones and teeth from the same individual were dated. Collagen contents ranged from 2.3 to $18.3 \%$, above the accepted cutoff value of 1\% (van Klinken 1999; Brock et al. 2010). $\mathrm{C} / \mathrm{N}$ ratios ranged from 3.07 to 3.53, within the accepted 2.9-3.6 range (DeNiro 1985; Ambrose 1990). Average collagen content was twice as high in teeth $(9.6 \pm 3.4 \%, n=27)$ than in bone $(4.5 \pm 2.4 \%, \mathrm{n}=20)$. On average, the $\mathrm{C} / \mathrm{N}$ ratio was lower in teeth $(3.26 \pm 0.06, \mathrm{n}=$ $27)$, than in bones $(3.36 \pm 0.13 \mathrm{n}=20)$. Radiocarbon ages ranged between $2630 \pm 25$ and $2925 \pm 25$ BP. On average, radiocarbon ages were lower in bones (2777 \pm 82 BP) BP than in teeth $(2835 \pm 45 \mathrm{BP})$. A negative correlation was found between the $\mathrm{C} / \mathrm{N}$ ratio and the ${ }^{14} \mathrm{C}$ age $(\mathrm{r} 2=0.68)$. No correlation was found between the collagen yield and the ${ }^{14} \mathrm{C}$ age $(\mathrm{r} 2=0.17)$, but the youngest ages were found in samples with less than 5\% collagen (SI Appendix, Fig. S4).

\section{Method 2}

A selection of 18 bone collagen extracts from the B10 complex was ultrafiltered. Results are summarized in the SI Appendix (Table S2 and Fig. S5). For five samples, both the highmolecular weight (HMW, > $30 \mathrm{KDa}$ ) and the low-molecular weight (LMW, <30 KDa) fractions were dated. For the remaining 13 samples, only the HMW fraction was dated. The $\mathrm{C} / \mathrm{N}$ ratios in HMW fractions ranged from 3.23 to 3.46 (3.34 \pm 0.07 on average), within the accepted range of 2.9-3.6. The $\mathrm{C} / \mathrm{N}$ ratio in LMW fractions were significantly higher, ranging from 3.41 to 3.62 (3.53 \pm 0.08 , on average) with one sample exceeding the accepted range (a petrous bone from $\mathrm{ST} 2, \mathrm{C} / \mathrm{N}=3.62$ ). Intra-individual differences in the $\mathrm{C} / \mathrm{N}$ ratio between the 
HMW and the LMW fraction ranged from 0.07 to 0.23 (average difference $0.13 \pm 0.06, n=5$ ). The radiocarbon ages of the HMW samples ranged from $2665 \pm 25$ to $2905 \pm 25$ BP (2805 \pm 58 , on average, $n=18$ ). The radiocarbon ages of the LMW samples were significantly lower and ranged from $2515 \pm 25$ to $2720 \pm 25 \mathrm{BP}(2629 \pm 83$, on average, $n=5)$. Intra-individual differences in radiocarbon age between the HMW and the LMW fraction ranged from 80 to $185{ }^{14} \mathrm{C}$ yr BP (average difference $126 \pm 46{ }^{14} \mathrm{C}$ yr BP, $\mathrm{n}=5$ ). 
Table S2. Results of the 100 AMS-radiocarbon analyses performed on charcoal (7), calcined bone (20) and bone and tooth collagen (73) from the B10 complex, the deer stone PAC38, and the khirgisuur KTS01.

\begin{tabular}{|c|c|c|c|c|c|c|c|c|c|c|c|c|c|c|c|}
\hline \multirow{2}{*}{$\begin{array}{l}\text { Structure } \\
\text { type }\end{array}$} & \multirow{2}{*}{ Feature } & \multirow{2}{*}{ Sample material } & \multirow{2}{*}{$\begin{array}{c}\text { Sample } \\
\text { detail }\end{array}$} & \multirow{2}{*}{$\delta^{13} \mathrm{C}_{\text {IRMS }}$} & \multirow{2}{*}{ Prep \# } & \multirow{2}{*}{ Target \# } & \multirow{2}{*}{$\begin{array}{l}\text { Collagen } \\
\text { extraction } \\
\text { Method }\end{array}$} & \multirow{2}{*}{$\begin{array}{l}\text { Yield } \\
(\%)\end{array}$} & \multirow{2}{*}[\mathrm{C}]{$\%$} & \multirow{2}{*}{$\begin{array}{l}\mathrm{C} / \mathrm{N} \\
\text { ratio }\end{array}$} & \multirow{2}{*}{$\begin{array}{l}{ }^{14} \mathrm{C} \\
\text { age }\end{array}$} & \multirow{2}{*}{ error } & \multicolumn{2}{|c|}{$\begin{array}{l}\text { Calibrated range } \\
\text { (IntCal13, 2s) }\end{array}$} & \multirow{2}{*}{$\begin{array}{l}\text { Outlier } \\
\text { Model }\end{array}$} \\
\hline & & & & & & & & & & & & & From & To & \\
\hline \multicolumn{16}{|c|}{ B10 Complex } \\
\hline \multirow{20}{*}{ Circles } & ST101 & calcined bone & - & -19.7 & 16363 & ECHo 1475 & - & 90.0 & - & - & 2845 & 20 & -1071 & -925 & Bone \\
\hline & ST102 & calcined bone & - & -21.1 & 16364 & ECHo 1489 & - & 89.9 & - & - & 2825 & 20 & -1042 & -916 & Bone \\
\hline & ST 102 & charcoal & - & -2 & 16341 & ECHo 1428 & - & 78.5 & 55.2 & - & 2900 & 20 & -1191 & -1010 & Charcoal \\
\hline & ST103 & calcined bone & - & -21.4 & 16365 & ECHo 1483 & - & 87.1 & - & - & 2855 & 20 & -1107 & -929 & Bone \\
\hline & ST 103.2 & charcoal & - & - & 16342 & ECHo 1429 & - & 59.5 & 41.7 & - & 2780 & 20 & -1000 & -849 & $\begin{array}{l}\text { excluded } \\
\text { from model }\end{array}$ \\
\hline & ST104 & calcined bone & - & -22.8 & 16366 & ECHo 1485 & - & 89.3 & - & - & 2845 & 20 & -1071 & -925 & Bone \\
\hline & ST107 & calcined bone & - & -20.9 & 16367 & ECHo 1487 & - & 89.9 & - & - & 2805 & 20 & -1008 & -907 & Bone \\
\hline & ST 107 & charcoal & - & - & 16343 & ЕСНо 1430 & - & 55.3 & 39.9 & - & 2810 & 25 & -1011 & -909 & Charcoal \\
\hline & ST108 & calcined bone & - & -21.4 & 16368 & ECHo 1472 & - & 89.4 & - & - & 2805 & 20 & -1006 & -904 & Bone \\
\hline & ST109 & calcined bone & - & -21.9 & 16369 & ECHo 1474 & - & 89.4 & - & - & 2810 & 20 & -1011 & -909 & Bone \\
\hline & ST 109.2 & charcoal & - & - & 16345 & ECHo 1432 & - & 52.5 & 49.3 & - & 2835 & 25 & -1071 & -913 & Charcoal \\
\hline & ST110 & calcined bone & - & -23.0 & 16370 & ECHo 1478 & - & 88.6 & - & - & 2790 & 20 & -1006 & -859 & Bone \\
\hline & ST105 & calcined bone & - & -21.7 & 16371 & ECHo 1477 & - & 86.9 & - & - & 2845 & 20 & -1071 & -925 & Bone \\
\hline & ST111 & calcined bone & - & -21.4 & 16372 & ЕСНо 1476 & - & 88.0 & - & - & 2855 & 20 & -1110 & -935 & Bone \\
\hline & ST 111 & charcoal & - & - & 16346 & ECHo 1433 & - & 69.1 & 51.1 & - & 2825 & 25 & -1042 & -916 & Charcoal \\
\hline & ST112 & calcined bone & - & -25.3 & 16373 & ECHo 1484 & - & 87.8 & - & - & 2845 & 20 & -1071 & -925 & Bone \\
\hline & ST113 & calcined bone & - & -22.5 & 16374 & ECHo 1480 & - & 88.4 & - & - & 2860 & 20 & -1111 & -941 & Bone \\
\hline & ST 113 & charcoal & - & - & 16347 & ECHo 1434 & - & 67.9 & 46.8 & - & 2910 & 25 & -1193 & -1019 & Charcoal \\
\hline & ST114 & calcined bone & - & -22.1 & 16375 & ECHo 1488 & - & 87.5 & - & - & 2785 & 20 & -1003 & -854 & Bone \\
\hline & ST115 & calcined bone & - & -23.4 & 16376 & ECHo 1479 & - & 88.6 & - & - & 2825 & 20 & -1023 & -912 & Bone \\
\hline
\end{tabular}




\begin{tabular}{|c|c|c|c|c|c|c|c|c|c|c|c|c|c|c|c|}
\hline & ST116 & calcined bone & - & -24.8 & 16377 & ЕСНо 1486 & - & 88.2 & - & - & 2805 & 20 & -1006 & -904 & Bone \\
\hline & ST117 & calcined bone & - & -24.1 & 16378 & ЕСНо 1482 & - & 87.6 & - & - & 2850 & 20 & -1107 & -929 & Bone \\
\hline & ST 117 & charcoal & - & - & 16350 & ЕСНо 1437 & - & 78.5 & 42.0 & - & 2815 & 25 & -1015 & -911 & Charcoal \\
\hline & ST118 & calcined bone & - & -25.4 & 16379 & ECHo 1470 & - & 88.1 & - & - & 2770 & 20 & -978 & -842 & Bone \\
\hline & $\mathrm{C} 476$ & calcined bone & - & -21.0 & 17017 & ECHo 1481 & - & 89.3 & - & - & 2830 & 20 & -1044 & -922 & Bone \\
\hline & C531 & calcined bone & - & -22.6 & 17018 & ECHo 1472 & - & 86.1 & - & - & 2840 & 20 & -1053 & -924 & Bone \\
\hline & C1162 & calcined bone & - & -21.6 & 17019 & ECHo 1473 & - & 86.7 & - & - & 2855 & 20 & -1110 & -935 & Bone \\
\hline \multirow{16}{*}{ Mounds } & ST 1 & left petrous bone & - & & 16322 & ECHo 1416 & 1 & 6.4 & & 3.19 & 2810 & 25 & -1025 & -901 & Bone \\
\hline & ST 1 & left petrous bone & - & & $\begin{array}{c}16322 \\
\mathrm{~A}\end{array}$ & $\begin{array}{c}\text { ECHo } \\
1687.1 .1\end{array}$ & 2 (HMW) & - & - & 3.34 & 2800 & 25 & -1016 & -858 & $\begin{array}{l}\text { excluded } \\
\text { from model }\end{array}$ \\
\hline & ST 1 & left petrous bone & - & 8 & $\begin{array}{c}16322 \\
\mathrm{~B}\end{array}$ & $\begin{array}{c}\text { ECHo } \\
1687.1 .2\end{array}$ & 2 (LMW) & - & - & 3.41 & 2720 & 25 & -911 & -815 & $\begin{array}{c}\text { excluded } \\
\text { from model }\end{array}$ \\
\hline & ST 2 & M1 sup G & - & & 17266 & $\begin{array}{c}\text { ECHo } \\
1804.1 .1\end{array}$ & 1 & 15.1 & - & 3.27 & 2845 & 25 & -1107 & -923 & Bone \\
\hline & ST 2 & left petrous bone & - & & $16323 \mathrm{~A}$ & $\begin{array}{c}\text { ECHo } \\
1673.1 .1 \\
\end{array}$ & 2 (HMW) & - & - & 3.39 & 2770 & 25 & -994 & -840 & $\begin{array}{l}\text { excluded } \\
\text { from model }\end{array}$ \\
\hline & ST 2 & left petrous bone & - & & $16323 \mathrm{~B}$ & $\begin{array}{c}\text { ECHo } \\
1673.1 .2\end{array}$ & 2 (LMW) & - & - & 3.62 & 2585 & 25 & -811 & -761 & $\begin{array}{l}\text { excluded } \\
\text { from model }\end{array}$ \\
\hline & ST 3 & left petrous bone & - & & 16324 & ЕСНо 1418 & 1 & 5.1 & - & 3.23 & 2915 & 25 & -1207 & -1021 & Bone \\
\hline & ST 3 & left petrous bone & - & & 16324B & $\begin{array}{c}\text { ECHo } \\
1688.1 .2 \\
\end{array}$ & 2 (LMW) & - & - & 3.40 & 2735 & 25 & -926 & -821 & $\begin{array}{l}\text { excluded } \\
\text { from model }\end{array}$ \\
\hline & ST 5 & left lower P2 & horse A & & 16327 & ECHo 1439 & 1 & 12.5 & - & 3.21 & 2840 & 25 & -1085 & -918 & Bone \\
\hline & ST 5 & left lower P2 & horse A & & $16327 \mathrm{~A}$ & $\begin{array}{c}\text { Echo } \\
1684.1 .1 \\
\end{array}$ & 2 (HMW) & & - & 3.23 & 2870 & 25 & -1121 & -940 & Bone \\
\hline & ST 5 & left petrous bone & horse B & & 16326 & ECHo 1438 & 1 & 8.4 & - & 3.16 & 2850 & 25 & -1109 & -928 & Bone \\
\hline & ST 6 & tooth indet & - & - & 16328 & ECHo 1420 & 1 & 3.3 & - & 3.07 & 2925 & 25 & -1214 & -1037 & $\begin{array}{l}\text { excluded } \\
\text { from model }\end{array}$ \\
\hline & ST 6 & tooth indet & - & - & $16328 \mathrm{~A}$ & $\begin{array}{c}\text { ECHo } \\
1675.1 .1\end{array}$ & 2 (HMW) & - & - & 3.36 & 2790 & 25 & -1009 & -851 & $\begin{array}{l}\text { excluded } \\
\text { from model }\end{array}$ \\
\hline & ST 8 & left petrous bone & horse A & - & 16325 & ECHo 1419 & 1 & 3.7 & - & 3.52 & 2715 & 25 & -908 & -813 & $\begin{array}{c}\text { excluded } \\
\text { from model }\end{array}$ \\
\hline & ST 8 & M1 sup D & horse A & - & 17267 & $\begin{array}{c}\text { ECHo } \\
1805.1 .1\end{array}$ & 1 & 8.9 & - & 3.28 & 2850 & 25 & -1109 & -928 & Bone \\
\hline & ST 8 & uper right third & horse A & - & 17021 & ECHo 1491 & 1 & 4.5 & - & 3.32 & 2820 & 25 & -1042 & -910 & excluded \\
\hline
\end{tabular}




\begin{tabular}{|c|c|c|c|c|c|c|c|c|c|c|c|c|c|c|}
\hline & molar & & & & & & & & & & & & & from model \\
\hline ST 8 & left petrous bone & horse A & - & $16325 \mathrm{~A}$ & $\begin{array}{c}\text { ECHo } \\
1689.1 .1\end{array}$ & 2 (HMW) & - & - & 3.46 & 2665 & 25 & -895 & -797 & $\begin{array}{l}\text { excluded } \\
\text { from model }\end{array}$ \\
\hline ST 8 & left petrous bone & horse A & - & $16325 \mathrm{~B}$ & $\begin{array}{c}\text { ECHo } \\
1689.1 .2\end{array}$ & $2(\mathrm{LMW})$ & - & - & 3.60 & 2515 & 25 & -791 & -543 & $\begin{array}{l}\text { excluded } \\
\text { from model }\end{array}$ \\
\hline ST 8 & $\begin{array}{l}\text { uper right third } \\
\text { molar }\end{array}$ & horse A & - & $17021 \mathrm{~A}$ & $\begin{array}{c}\text { ECHo } \\
1678.1 .1 \\
\end{array}$ & 2 (HMW) & - & - & 3.32 & 2850 & 25 & -1109 & -928 & $\begin{array}{l}\text { excluded } \\
\text { from model }\end{array}$ \\
\hline ST 8 & left petrous bone & horse B & - & 16329 & ECHo 1421 & 1 & 4.6 & - & 3.30 & 2915 & 25 & -1207 & -1021 & $\begin{array}{l}\text { excluded } \\
\text { from model }\end{array}$ \\
\hline ST 8 & left petrous bone & horse B & - & 16329A & $\begin{array}{c}\text { ECHo } \\
1676.1 .1 \\
\end{array}$ & 2 (HMW) & - & - & 3.41 & 2810 & 25 & -1025 & -901 & $\begin{array}{l}\text { excluded } \\
\text { from model }\end{array}$ \\
\hline ST 9 & left petrous bone & & - & $16330 \mathrm{~A}$ & $\begin{array}{l}\text { ECHo } \\
1677.1 .1\end{array}$ & 2 (HMW) & - & - & 3.30 & 2840 & 25 & -1085 & -918 & Bone \\
\hline ST 10 & lower premolar & & - & 16331 & ECHo 1422 & 1 & 8.6 & - & 3.25 & 2780 & 25 & -1002 & -846 & Bone \\
\hline ST 11 & upper tooth & & - & 16332 & ECHo 1441 & 1 & 8.8 & - & 3.30 & 2745 & 25 & -970 & -826 & Bone \\
\hline ST11 & cervical bone & & - & $16333 \mathrm{~A}$ & $\begin{array}{c}\text { ECHo } \\
1685.1 .1 \\
\end{array}$ & 2 (HMW) & & - & 3.28 & 2805 & 25 & -1023 & -897 & Bone \\
\hline ST12 & left third premolar & & - & 16334 & ECHo 1424 & 1 & 8.7 & - & 3.15 & 2835 & 20 & -1047 & -925 & Bone \\
\hline ST 14 & $\begin{array}{l}\text { lower right first } \\
\text { molar }\end{array}$ & & - & 16335 & ECHo 1442 & 1 & 4.9 & - & 3.33 & 2755 & 25 & -974 & -831 & $\begin{array}{l}\text { excluded } \\
\text { from model }\end{array}$ \\
\hline ST 14 & lower left P2 & & - & 17268 & $\begin{array}{c}\text { ECHo } \\
1806.1 .1\end{array}$ & 1 & 18.3 & - & 3.23 & 2855 & 25 & -1111 & -934 & Bone \\
\hline ST 15 & lower left P2 & & - & 17269 & $\begin{array}{c}\text { ECHo } \\
1807.1 .1 \\
\end{array}$ & 1 & 9.9 & - & 3.25 & 2875 & 25 & -1126 & -941 & Bone \\
\hline ST 15 & right petrous bone & & - & 16336 & ECHo 1425 & 1 & 4.7 & - & 3.46 & 2645 & 20 & -831 & -796 & $\begin{array}{c}\text { excluded } \\
\text { from model }\end{array}$ \\
\hline ST 15 & right petrous bone & & - & $16336 \mathrm{~B}$ & $\begin{array}{c}\text { ECHo } \\
1674.1 .2 \\
\end{array}$ & 2 (LMW) & - & - & 3.50 & 2695 & 25 & -900 & -807 & $\begin{array}{l}\text { excluded } \\
\text { from model }\end{array}$ \\
\hline ST 15 & right petrous bone & & - & $16336 \mathrm{~A}$ & $\begin{array}{c}\text { Echo } \\
1674.1 .1\end{array}$ & 2 (HMW) & - & - & 3.40 & 2775 & 25 & -996 & -845 & $\begin{array}{l}\text { excluded } \\
\text { from model }\end{array}$ \\
\hline ST 16 & left petrous bone & & - & 16337 & ECHo 1426 & 1 & 2.9 & - & 3.46 & 2685 & 25 & -896 & -804 & $\begin{array}{l}\text { excluded } \\
\text { from model }\end{array}$ \\
\hline ST 16 & upper left P2 & & - & 17270 & $\begin{array}{c}\text { ECHo } \\
1808.1 .1\end{array}$ & 1 & 9.8 & - & 3.27 & 2825 & 25 & -1047 & -913 & Bone \\
\hline ST 17 & left second molar & & - & 16338 & ЕСНо 1415 & 1 & 12.1 & - & 3.29 & 2805 & 25 & & & Bone \\
\hline ST 17 & left second molar & & - & $16338 \mathrm{~A}$ & ECHo & 2 (HMW) & & - & 3.29 & 2905 & 25 & -1195 & -1011 & Bone \\
\hline
\end{tabular}




\begin{tabular}{|c|c|c|c|c|c|c|c|c|c|c|c|c|c|}
\hline & & & & 1686.1.1 & & & & & & & & & \\
\hline ST 18 & left petrous bone & - & 16339 & ЕСНo 1427 & 1 & 5.1 & - & 3.41 & 2790 & 20 & -1006 & -859 & $\begin{array}{l}\text { excluded } \\
\text { from model }\end{array}$ \\
\hline ST 18 & lower right $\mathrm{P} / \mathrm{M}$ & - & 17271 & $\begin{array}{c}\text { ECHo } \\
1809.1 .1\end{array}$ & 1 & 8.6 & - & 3.24 & 2860 & 25 & -1115 & -935 & Bone \\
\hline SAT 354 & upper right $\mathrm{P} / \mathrm{M}$ & - & 17260 & $\begin{array}{c}\text { ECHo } \\
1798.1 .1 \\
\end{array}$ & 1 & 14.8 & - & 3.22 & 2880 & 25 & -1188 & -946 & Bone \\
\hline SAT 354 & lower right $\mathrm{M}$ & - & 14429 & SacA39453 & 1 & 7.9 & - & - & 2845 & 30 & -1110 & -921 & Bone \\
\hline SAT 397 & upper left P2 & - & 17261 & $\begin{array}{c}\text { ECHo } \\
1799.1 .1\end{array}$ & 1 & 13.2 & - & 3.24 & 2900 & 25 & -1193 & -1008 & Bone \\
\hline SAT 415 & upper right $\mathrm{P} 2$ & - & 17262 & $\begin{array}{c}\text { ECHo } \\
1800.1 .1\end{array}$ & 1 & 12.2 & - & 3.25 & 2840 & 25 & -1085 & -918 & Bone \\
\hline SAT 416 & upper right $\mathrm{P} / \mathrm{M}$ & - & 17263 & $\begin{array}{c}\text { ECHo } \\
1801.1 .1\end{array}$ & 1 & 10.1 & - & 3.23 & 2865 & 30 & -1118 & -937 & Bone \\
\hline SAT 528 & tooth indet & - & 17022 & ECHo 1492 & 1 & 11.8 & - & 3.32 & 2790 & 25 & -1009 & -851 & $\begin{array}{c}\text { excluded } \\
\text { from model }\end{array}$ \\
\hline SAT 528 & tooth indet & - & $17022 \mathrm{~A}$ & $\begin{array}{c}\text { ECHo } \\
1679.1 .1 \\
\end{array}$ & 2 (HMW) & - & - & 3.29 & 2815 & 25 & -1028 & -905 & Bone \\
\hline SAT 532 & bone indet & - & 17023 & ECHo 1493 & 1 & 3.7 & - & 3.42 & 2685 & 25 & -896 & -804 & $\begin{array}{l}\text { excluded } \\
\text { from model }\end{array}$ \\
\hline SAT 532 & bone indet & - & $17023 \mathrm{~A}$ & $\begin{array}{c}\text { ECHo } \\
1690.1 .1\end{array}$ & 2 (HMW) & - & - & 3.37 & 2710 & 25 & -905 & -811 & $\begin{array}{l}\text { excluded } \\
\text { from model }\end{array}$ \\
\hline SAT 533 & bone indet & - & 17024 & ЕСНо 1494 & 1 & 3.1 & - & 3.53 & 2630 & 25 & -830 & -789 & $\begin{array}{l}\text { excluded } \\
\text { from model }\end{array}$ \\
\hline SAT 533 & bone indet & - & 17024A & $\begin{array}{c}\text { ECHo } \\
1693.1 .1\end{array}$ & 2 (HMW) & - & - & 3.43 & 2765 & 25 & -978 & -836 & $\begin{array}{l}\text { excluded } \\
\text { from model }\end{array}$ \\
\hline SAT 533 & bone indet & - & 17024B & $\begin{array}{c}\text { ECHo } \\
1693.1 .2\end{array}$ & $2(\mathrm{LMW})$ & - & - & 3.54 & 2630 & 25 & -830 & -789 & $\begin{array}{l}\text { excluded } \\
\text { from model }\end{array}$ \\
\hline SAT 666 & $M \sup D$ & - & 17264 & $\begin{array}{c}\text { ECHo } \\
1802.1 .1 \\
\end{array}$ & 1 & 7.7 & - & 3.27 & 2820 & 25 & -1042 & -910 & Bone \\
\hline SAT 732 & left dP3 & - & 14430 & SacA39454 & 1 & 6.8 & - & 3.25 & 2885 & 30 & -1193 & -946 & Bone \\
\hline SAT 799 & $\mathrm{P} / \mathrm{M} \sup \mathrm{G}$ & - & 17265 & $\begin{array}{c}\text { ECHo } \\
1803.1 .1 \\
\end{array}$ & 1 & 11.8 & - & 3.25 & 2845 & 30 & -1110 & -921 & Bone \\
\hline SAT 799 & petrous bone & - & 17025 & ECHo 1495 & 1 & 2.5 & - & 3.49 & 2720 & 20 & -906 & -820 & $\begin{array}{l}\text { excluded } \\
\text { from model }\end{array}$ \\
\hline SAT 803 & tooth indet & - & 17026 & ECHo 1496 & 1 & 10.7 & - & 3.32 & 2745 & 25 & -970 & -826 & $\begin{array}{l}\text { excluded } \\
\text { from model }\end{array}$ \\
\hline
\end{tabular}




\begin{tabular}{|c|c|c|c|c|c|c|c|c|c|c|c|c|c|c|c|}
\hline & SAT 803 & tooth indet & & - & $17026 \mathrm{~A}$ & $\begin{array}{c}\text { ECHo } \\
1680.1 .1 \\
\end{array}$ & 2 (HMW) & - & - & 3.31 & 2800 & 25 & -1016 & -858 & $\begin{array}{l}\text { excluded } \\
\text { from model }\end{array}$ \\
\hline & SAT 810 & tooth indet & & - & 17027 & ЕСНо 1497 & 1 & 7.3 & - & 3.27 & 2835 & 25 & -1071 & -913 & Bone \\
\hline & SAT 810 & tooth indet & & - & $17027 \mathrm{~A}$ & $\begin{array}{c}\text { ECHo } \\
1681.1 .1 \\
\end{array}$ & 2 (HMW) & & - & 3.24 & 2850 & 25 & -1109 & -928 & Bone \\
\hline & SAT 811 & petrous bone & horse A & - & 17028 & ECHo 1498 & 1 & 5.0 & - & 3.36 & 2815 & 25 & -1028 & -905 & $\begin{array}{c}\text { excluded } \\
\text { from model }\end{array}$ \\
\hline & SAT 811 & tooth indet & horse B & - & 17029 & ECHo 1499 & 1 & 7.4 & - & 3.30 & 2805 & 20 & -1008 & -907 & Bone \\
\hline & SAT 811 & petrous bone & horse A & - & $17028 \mathrm{~A}$ & $\begin{array}{c}\text { ECHo } \\
1682.1 .1\end{array}$ & 2 (HMW) & - & - & 3.30 & 2865 & 25 & -1118 & -937 & Bone \\
\hline & SAT 811 & tooth indet & horse B & - & $17029 \mathrm{~A}$ & $\begin{array}{c}\text { ECHo } \\
1683.1 .1 \\
\end{array}$ & 2 (HMW) & - & - & 3.26 & 2835 & 25 & -1071 & -913 & Bone \\
\hline & $\begin{array}{l}\text { SAT } \\
1023 \\
\end{array}$ & P2sup G & horse A & - & 17258 & $\begin{array}{c}\text { ECHo } \\
1796.1 .1 \\
\end{array}$ & 1 & 5.6 & - & 3.22 & 2865 & 25 & -1118 & -937 & Bone \\
\hline & $\begin{array}{l}\text { SAT } \\
1023 \\
\end{array}$ & M2 sup D & horse B & - & 17259 & $\begin{array}{c}\text { ECHo } \\
1797.1 .1 \\
\end{array}$ & 1 & 9.5 & - & 3.25 & 2840 & 25 & -1085 & -918 & Bone \\
\hline \multicolumn{16}{|c|}{ Khirgisuur KTS01 } \\
\hline \multirow{6}{*}{ Mounds } & S1 & petrous bone & - & - & 17272 & $\begin{array}{c}\text { ECHo } \\
1810.1 .1 \\
\end{array}$ & 1 & 4.9 & - & 3.41 & 2785 & 25 & -1006 & -847 & $\begin{array}{c}\text { excluded } \\
\text { from model }\end{array}$ \\
\hline & $\mathrm{S} 2$ & M sup & - & - & 17273 & $\begin{array}{c}\text { ECHo } \\
1811.1 .1 \\
\end{array}$ & 1 & 11.9 & - & 3.23 & 2880 & 25 & -1188 & -946 & Bone \\
\hline & S3 & petrous bone & - & - & 17274 & $\begin{array}{c}\text { ECHo } \\
1812.1 .1 \\
\end{array}$ & 1 & 8.7 & - & 3.30 & 2845 & 25 & -1107 & -923 & $\begin{array}{c}\text { excluded } \\
\text { from model }\end{array}$ \\
\hline & S4 & petrous bone & - & - & 17275 & $\begin{array}{c}\text { ECHo } \\
1813.1 .1 \\
\end{array}$ & 1 & 6 & - & 3.44 & 2820 & 25 & -1042 & -910 & $\begin{array}{l}\text { excluded } \\
\text { from model }\end{array}$ \\
\hline & S5 & M sup & - & - & 17276 & $\begin{array}{c}\text { ECHo } \\
1814.1 .1 \\
\end{array}$ & 1 & 14.9 & - & 3.24 & 2890 & 25 & -1193 & -998 & Bone \\
\hline & S6 & petrous bone & - & - & 17277 & $\begin{array}{c}\text { ECHo } \\
1815.1 .1 \\
\end{array}$ & 1 & 4.7 & - & 3.51 & 2785 & 25 & -1006 & -847 & $\begin{array}{l}\text { excluded } \\
\text { from model }\end{array}$ \\
\hline \multicolumn{16}{|c|}{ Deer stone PAC38 } \\
\hline \multirow{3}{*}{ Mounds } & PAC38-1 & P2 inf G & - & - & 17278 & $\begin{array}{c}\text { ECHo } \\
1816.1 .1 \\
\end{array}$ & 1 & 15 & - & 3.23 & 2860 & 25 & -1115 & -935 & Bone \\
\hline & \begin{tabular}{|c|} 
PAC38- \\
27 \\
\end{tabular} & tooth indet & - & - & 17279 & $\begin{array}{c}\text { ECHo } \\
1817.1 .1 \\
\end{array}$ & 1 & 15.4 & - & 3.24 & 2840 & 25 & -1085 & -918 & Bone \\
\hline & \begin{tabular}{|c|} 
PAC38- \\
95 \\
\end{tabular} & P2 sup D & - & - & 17280 & $\begin{array}{c}\text { ECHo } \\
1818.1 .1 \\
\end{array}$ & 1 & 16 & - & 3.21 & 2840 & 25 & -1085 & -918 & Bone \\
\hline
\end{tabular}


Figure S2. Left panel: comparison of radiocarbon dates of charcoal and calcined bones in six circles from the B10 complex. Right panel: radiocarbon age (average $\pm \mathrm{SD}, \mathrm{n}=6$ ) for charcoal (black circle) and calcined bone (open circle).

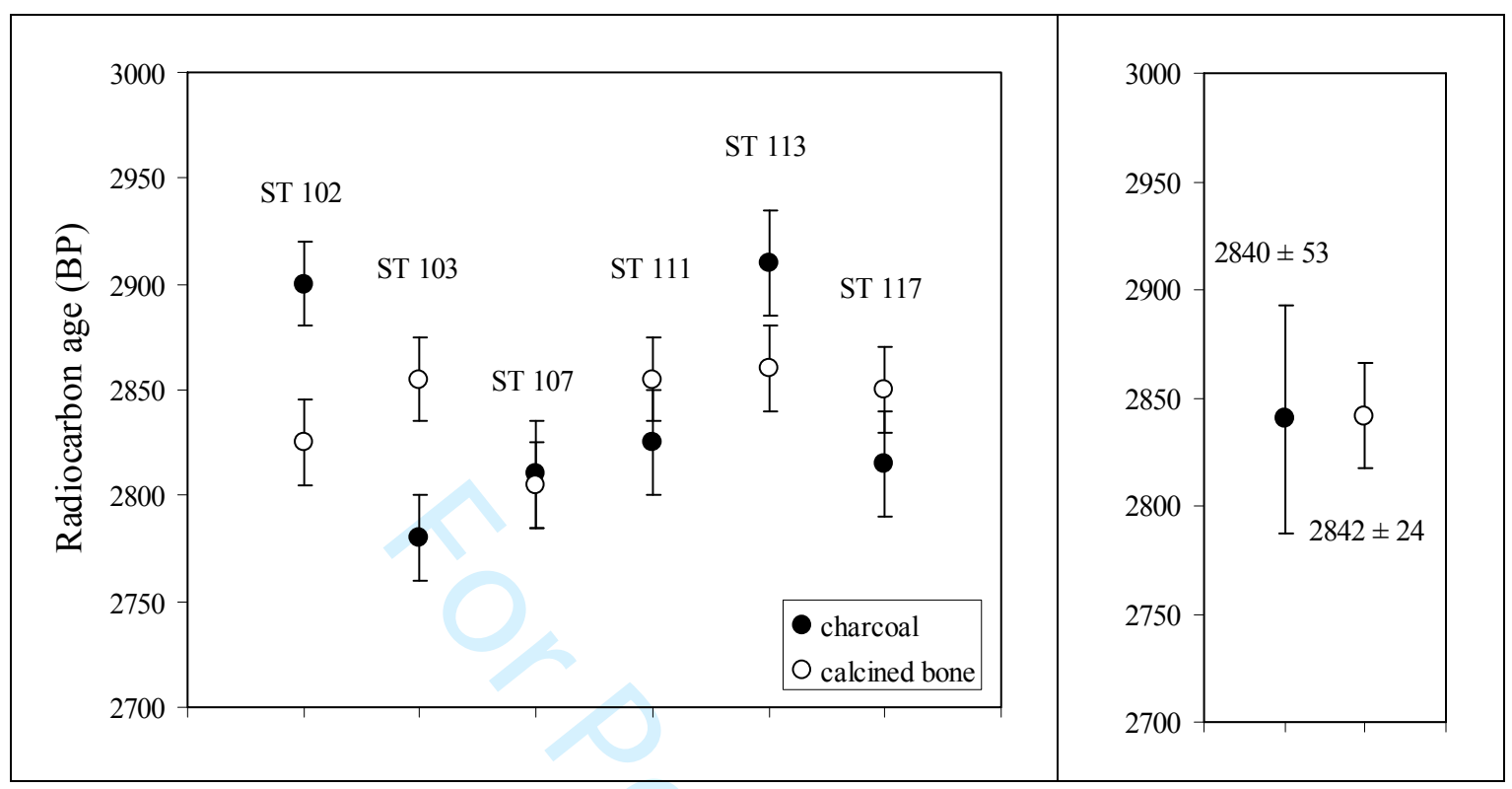


Figure S3. Top panel: relationship between bone and tooth collagen radiocarbon age and $\mathrm{C} / \mathrm{N}$ ratio at KTS01. Bottom panel: relationship between bone and tooth collagen radiocarbon age and collagen yield at KTS01. Collagen was extracted using Method 1.

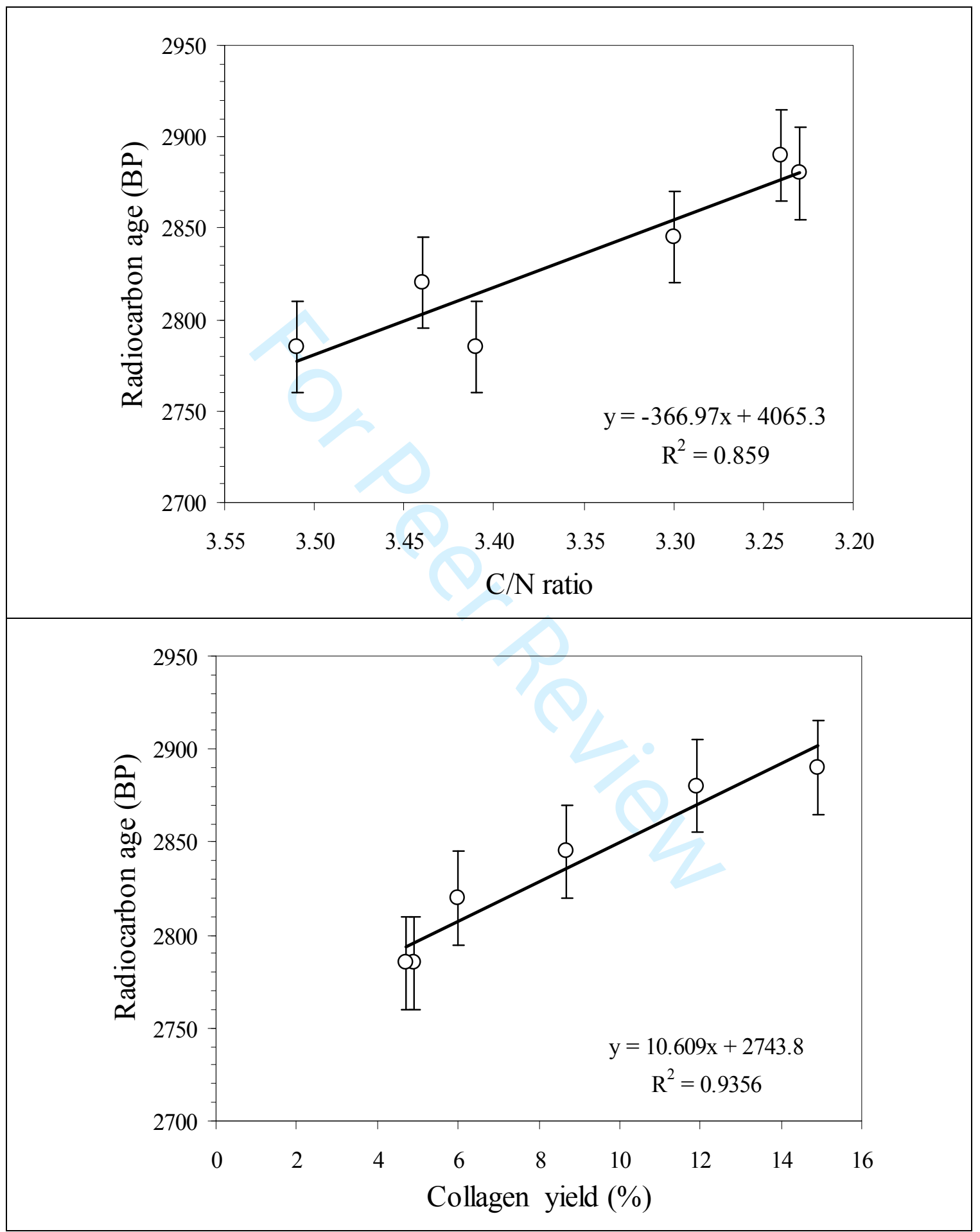


Figure S4. Top panel: relationship between bone and tooth collagen radiocarbon age and $\mathrm{C} / \mathrm{N}$ ratio at the $\mathrm{B} 10$ complex. Bottom panel: relationship between bone and tooth collagen radiocarbon age and yield at the B10 complex. Collagen was extracted using Method 1.

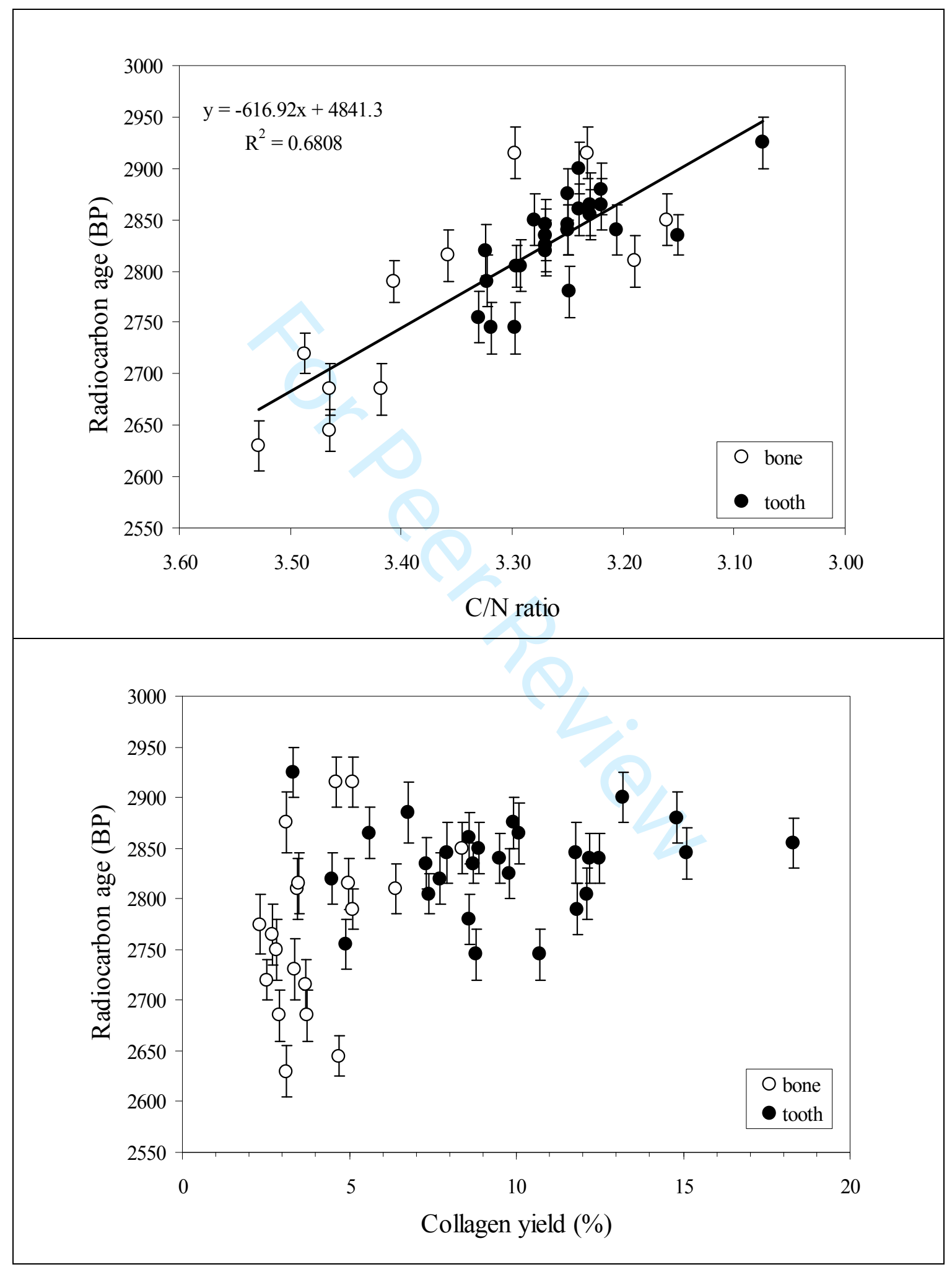


Figure S5. Top panel: comparison of radiocarbon dates of high molecular weight (HMW, > $30 \mathrm{KDa}$ ) and low molecular weight (LMW, $<30 \mathrm{KDa}$ ) fractions of six ultrafiltered collagen samples prepared using Method 2 (see Table S2 for details). Bottom panel: comparison of $\mathrm{C} / \mathrm{N}$ ratios of high molecular weight (HMW, $>30 \mathrm{KDa}$ ) and low molecular weight (LMW, < $30 \mathrm{KDa}$ ) fractions of six ultrafiltered collagen samples prepared using Method 2.

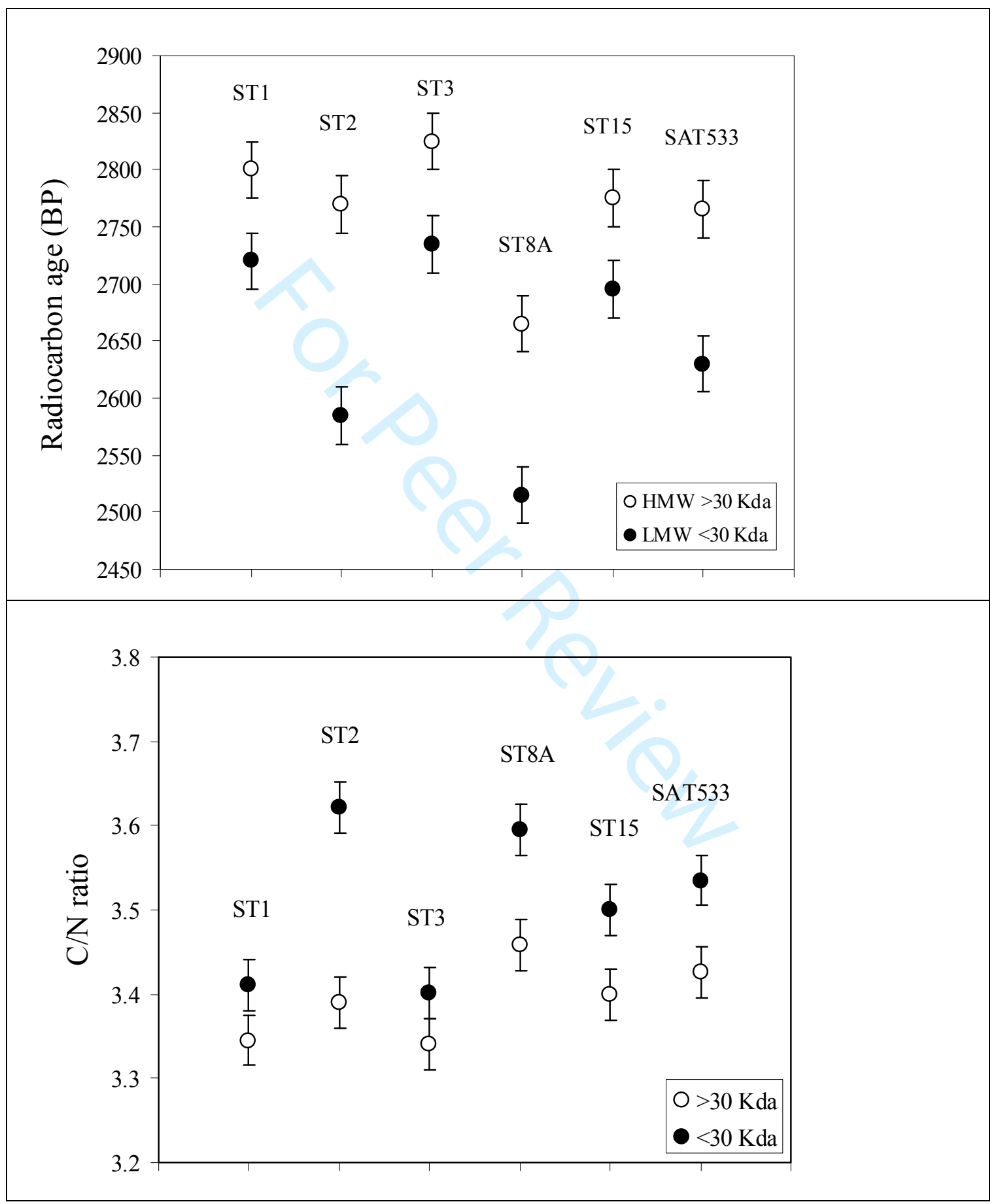


Figure S6. Left panel: Comparison of radiocarbon dates of collagen samples prepared using Method 1 (no ultrafiltration) and Method 2 (ultrafiltration, HMW fraction). Right panel: Radiocarbon age (average $\pm \mathrm{SD}, \mathrm{n}=15$ ) for each method.

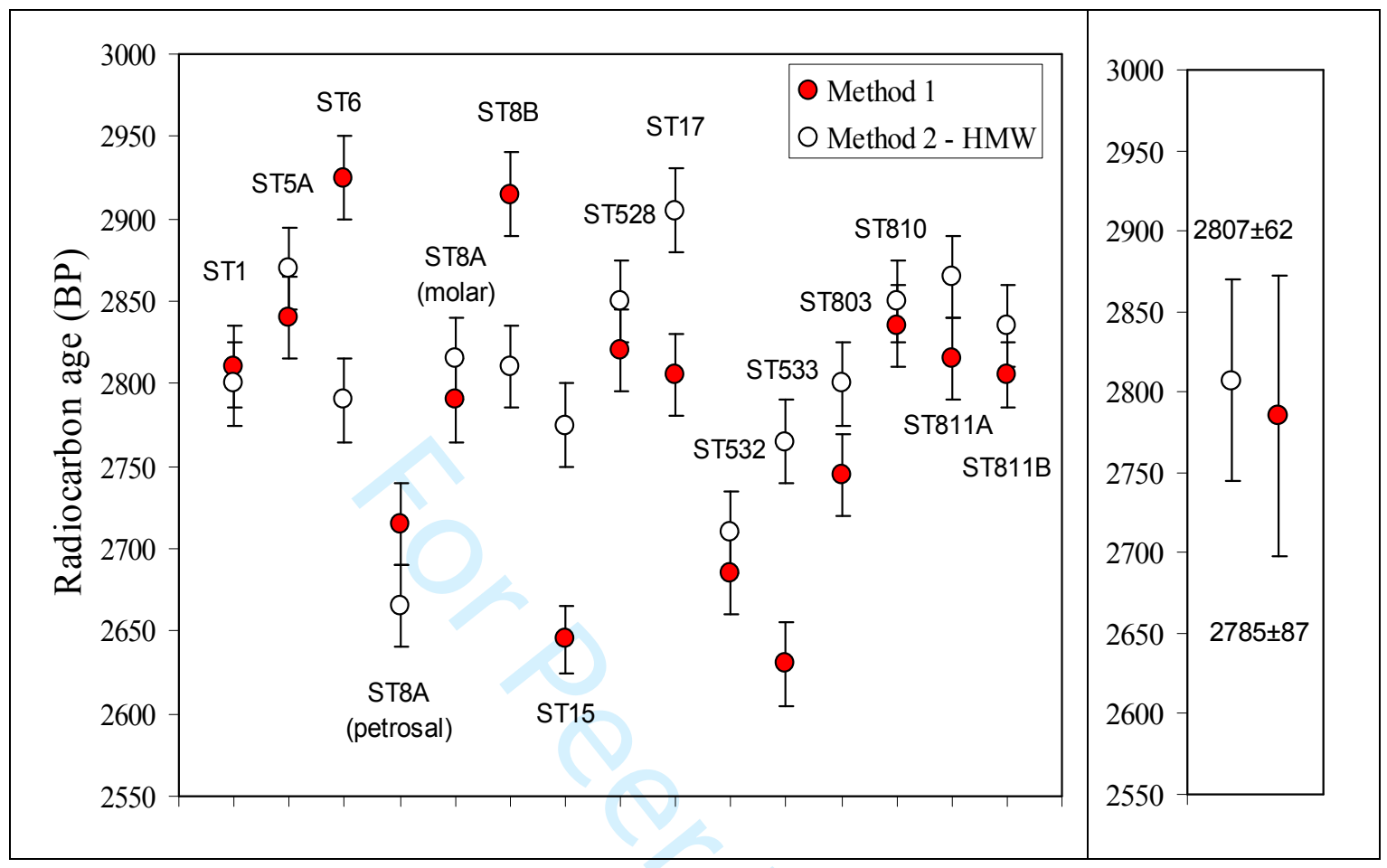




\section{S.4. Modeling}

\section{S4.A. Tsatsyn model}

The model used only weak or non informative prior to estimate the onset, duration and end of use of the B10 complex, PAC38 and KTS01. We used the resulting sample of 62 dates to produce a Bayesian model containing three phases corresponding to the three dated monuments, with a uniform prior using the $\mathrm{OxCal}$ and the IntCal 13 radiocarbon calibration curve (Bronk-Ramsey \& Lee 2013). We then used the OxCal 'Order' function in order to test the chronological ordering between the different monuments. We repeated this analysis once with an outlier model which identifies and downweights anomalous measurements (Bronk Ramsey 2009). Two different outlier models were used for the charcoal and bones, respectively.

The outlier-model used for the charcoal ("Charcoal") was a Normal "t" outlier-analysis model postulating an a priori outlier probability of 5\% for every sample following (Bronk Ramsey 2009). We used this outlier-model because we could not exclude that the charcoal was either too old due to an old-wood effect or too young due to contamination. The outlier-model used for calcined bone and bone collagen ("Bone") is a negative exponential model postulating an a priori outlier probability of $100 \%$ for every sample. We used this model because we postulated that bones were all in a primary position and could only be too young due to contamination with modern carbon.

Both models produced similar results, but only results from the outlier model are reported here. The model was run five times to assess its reproducibility and the data from one of the runs are shown in Table 1. 


\section{SQL Code for the Tsatsyn Outlier Model}

\begin{tabular}{|c|c|}
\hline 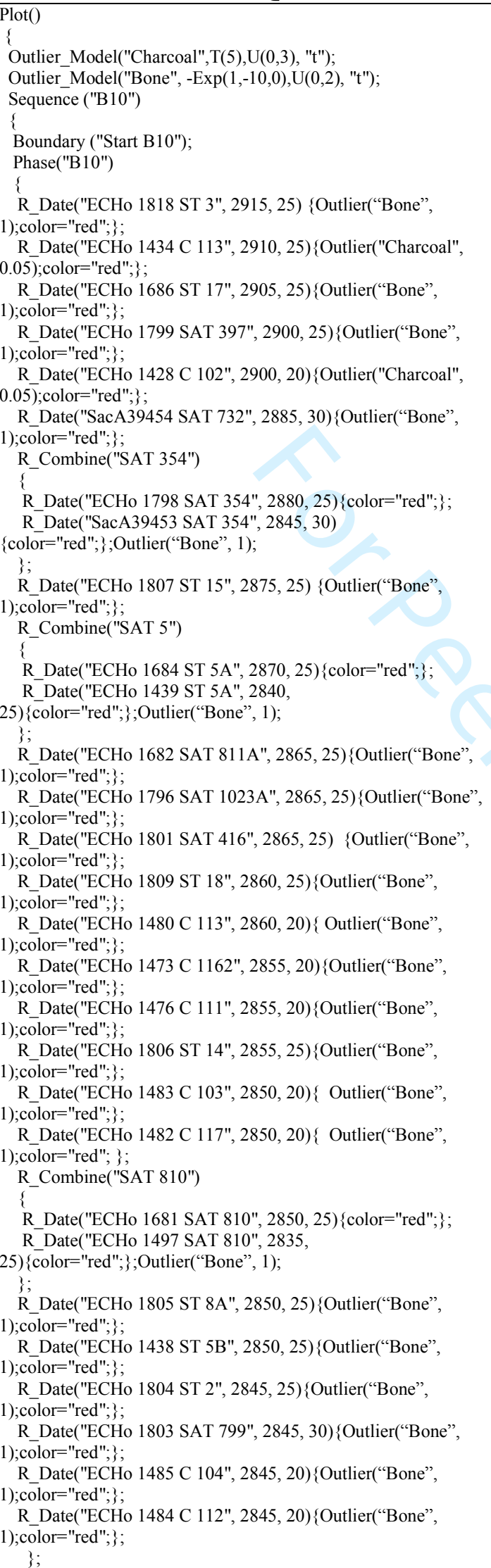 & 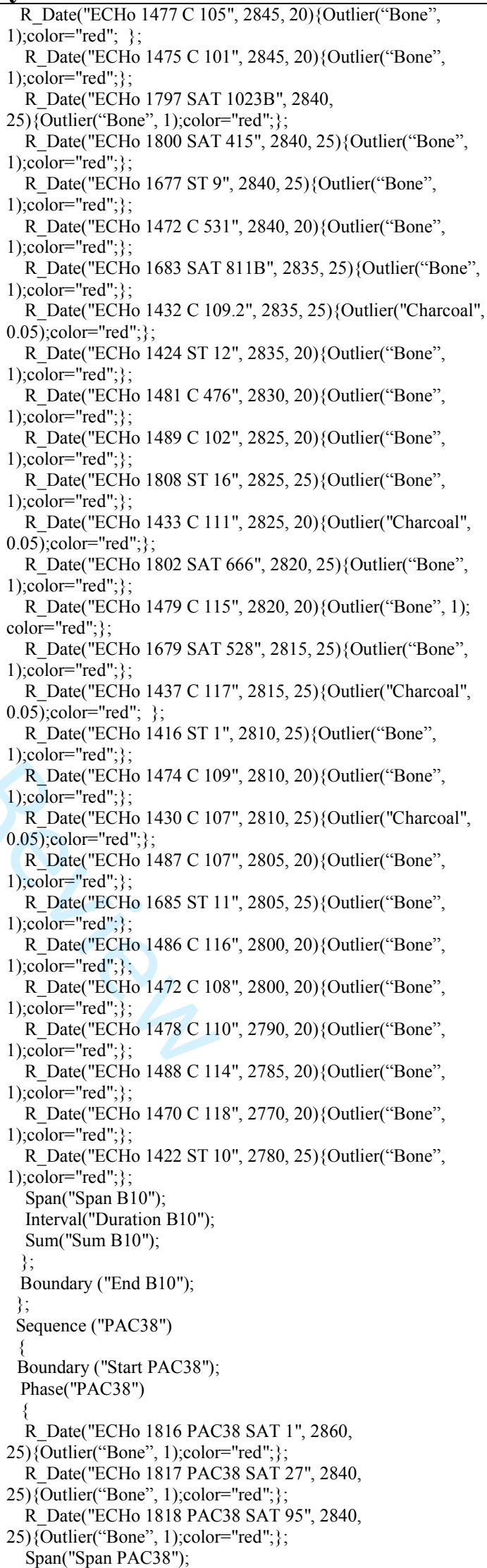 \\
\hline
\end{tabular}




\begin{tabular}{|l|l|}
\hline Sequence ("KTS01") & Interval("Duration PAC38"); \\
\{ & Sum("Sum PAC38"); \\
Boundary ("Start KTS01"); & Boundary ("End PAC38"); \\
Phase("KTS01") & \\
\{ & \\
R_Date("ECHo 1811 KTS01-S2", 2880, 25)\{Outlier("Bone", & \\
1);color="red";\}; & \\
R_Date("ECHo 1817 KTS01-S5", 2890, 25)\{Outlier("Bone", & \\
1);color="red";\}; & \\
Span("Span KTS01"); & \\
Interval("Duration KTS01"); & \\
Sum("Sum KTS01"); & \\
\}; & \\
Boundary ("End KTS01"); & \\
\}; & \\
Order() & \\
\{ & \\
Prior("Start B10","0Start_B10.prior"); & \\
Prior("Start PAC38","0Start_PAC38.prior"); & \\
Prior("Start KTS01","0Start_KTS01.prior"); & \\
\}; & \\
\hline
\end{tabular}




\section{S4.B. Model 0}

The model uses fifty fictitious radiocarbon dates to estimate the onset, span and end of use of the B10 complex. Here we postulate that the B10 complex was constructed in an instant. The radiocarbon distributions have been simulated by a process of back-calibration from samples whose real age is $1000 \mathrm{cal} \mathrm{BC}$. All the dates are grouped in a single phase to produce the Bayesian model, with a uniform prior using the OxCal and the IntCal13 radiocarbon calibration curve (Bronk-Ramsey \& Lee 2013). The model was run five times to assess its reproducibility and the data from one of the runs are shown in Table 3.

\section{SQL Code for the Model 0}

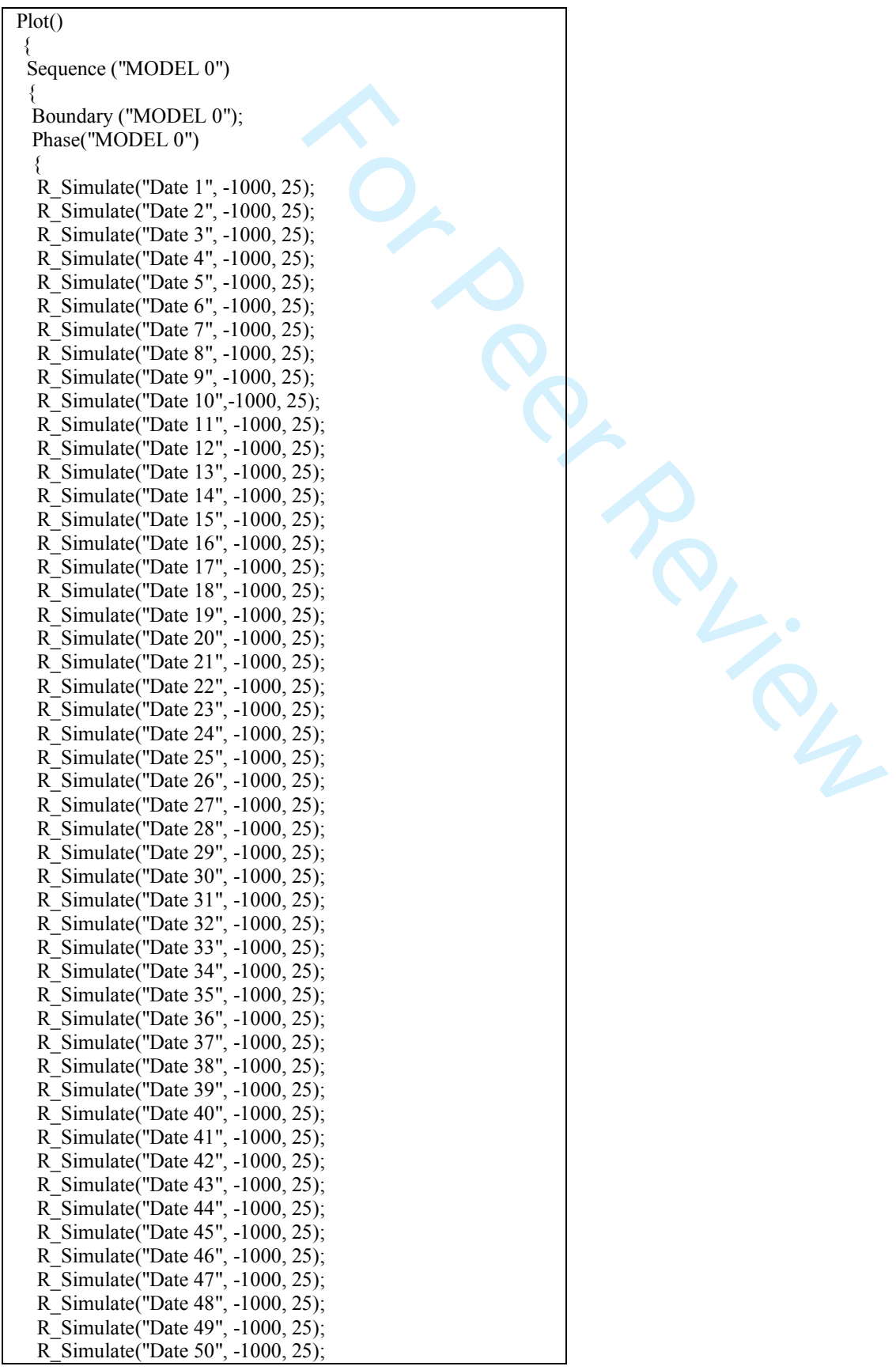


Span("MODEL 0");

Interval ("MODEL 0");

;

Boundary ("End MODEL 00");

\};

; 


\section{S4.C. Model 50}

The model uses fifty fictitious radiocarbon dates to estimate the onset, span and end of use of the B10 complex. Here we postulate that the B10 complex was constructed over fifty years. The radiocarbon distributions have been simulated by a process of back-calibration from samples whose real age range between 1025 and 976 cal BC. All the dates are grouped in a single phase to produce the Bayesian model, with a uniform prior using the OxCal and the IntCal13 radiocarbon calibration curve (Bronk-Ramsey \& Lee 2013). The model was run five times to assess its reproducibility and the data from one of the runs are shown in Table 3.

\section{SQL Code for the Model 50}

\begin{tabular}{|c|}
\hline 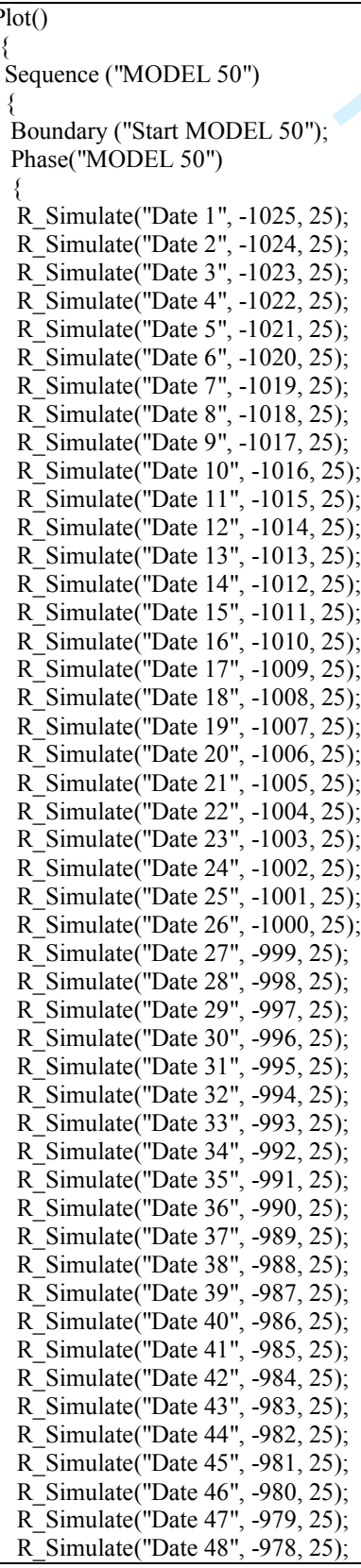 \\
\hline
\end{tabular}


R Simulate("Date 49", -977, 25);

R_Simulate("Date 50", -976, 25);

Span("MODEL 50");

Interval ("MODEL 50");

;

Boundary ("End MODEL 50");

;

;; 


\section{S4.D. Model 100}

The model uses fifty fictitious radiocarbon dates to estimate the onset, span and end of use of the B10 complex. Here we postulate that the B10 complex was constructed over a hundred years. The radiocarbon distributions have been simulated by a process of back-calibration from samples whose real age range between 1050 and 950 cal BC. All the dates are grouped in a single phase to produce the Bayesian model, with a uniform prior using the OxCal and the IntCal13 radiocarbon calibration curve (Bronk-Ramsey \& Lee 2013). The model was run five times to assess its reproducibility and the data from one of the runs are shown in Table 3.

\section{SQL Code for the Model 100}

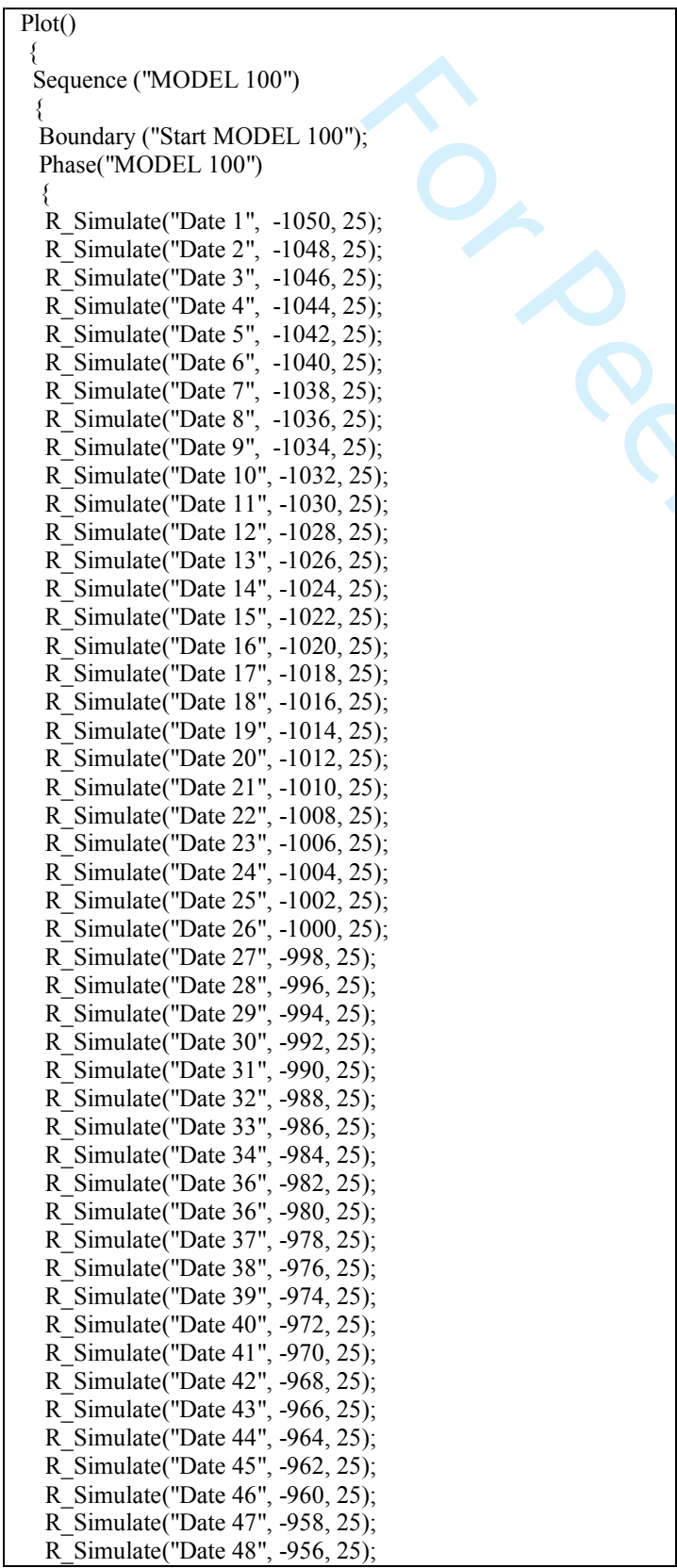


R Simulate("Date 49", -953, 25);

R_Simulate("Date 50", -950, 25);

Span("MODEL 100");

Interval ("MODEL 100");

;

Boundary ("End MODEL 100");

;

; 


\section{Reference list}

AlLARD, F. \& D. ERDENEBAATAR. 2005. Khirigsuurs, ritual and mobility in the Bronze Age of Mongolia. Antiquity 79: 547-63.

AmBrose, S.H. 1990. Preparation and characterization of bone and tooth collagen for isotopic analysis Journal of Archaeological Science 17: 431-51.

Bocherens, H., M. Fizet., A. MARIOTTI., B. LANGe-BADRE., B. VANDERMEersCH., J.P. Borel. \& G. BELLON. 1991. Isotopic biogeochemistry $(13 \mathrm{C}, 15 \mathrm{~N})$ of fossil vertebrate collagen: application to the study of a past food web including Neandertal man Journal of Human Evolution 20: 481-92.

BROCK, F., T. HighAM. \& C.B. RAMSEY. 2010. Pre-screening techniques for identification of samples suitable for radiocarbon dating of poorly preserved bones Journal of Archaeological Science 37: 855-65.

BRONK RAMSEY, C. 2009. Dealing with Outliers and Offsets in Radiocarbon Dating Radiocarbon 51: 1023-45. Cambridge Core.

BRonK-RAMSEY, C. \& S. LeE. 2013. Recent and Planned Developments of the Program OxCal Radiocarbon 55: 720-30.

DENIRO, M.J. 1985. Postmortem preservation and alteration of in vivo bone collagen isotope ratios in relation to palaeodietary reconstruction Nature 317: 806-9.

Fitzhugh, W. \& J. BAYARSAIKHAN. 2009. American-Mongolian Deer Stone Project: Field Report 2009. Arctic Studies Center. Washington, DC: Smithsonian Institution.

GANTULGA, J.-O. 2015. Recherches sur les monuments funéraires des nomades de l'Age du bronze et du début de l'Age du fer en Mongolie. Thèse de Doctorat de l’Université de Bourgogne Franche Comté.

MAgaIL, J. 2008. Tsatsiin Ereg, site majeur du début du Ier millénaire en Mongolie Bulletin d'anthropologie préhistorique de Monaco 48.

TAYLOR, W., B. JARgalan., K. LOWRY., J. Clark., T. TUVShinjargal. \& J. BAYARSAIKHAN. 2017. A Bayesian chronology for early domestic horse use in the Eastern Steppe Journal of Archaeological Science 81: 49-58.

VAN KLINKEN, G.J. 1999. Bone Collagen Quality Indicators for Palaeodietary and Radiocarbon Measurements Journal of Archaeological Science 26: 687-95. 